\title{
Nondestructive Testing Methods for 55-Gallon, Waste Storage Drums
}

\author{
R. H. Ferris \\ B. P. Hildebrand \\ R. L. Hockey \\ D. M. Riechers \\ J. C. Spanner \\ Pacific Northwest Laboratory \\ D. R. Duncan \\ Westinghouse Hanford Company \\ Date Published \\ June 1993
}

Prepared for the U.S. Department of Energy Office of Environmental Restoration and

Waste Management

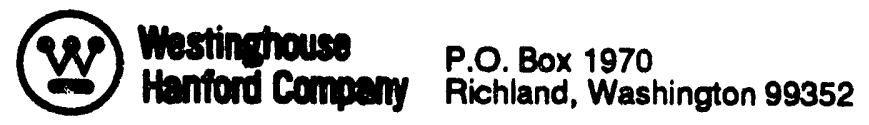

Hanford Operations and Engineering Contractor for the

U.S. Department of Energy under Contract DE-AC06-87RL10930

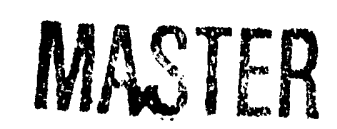

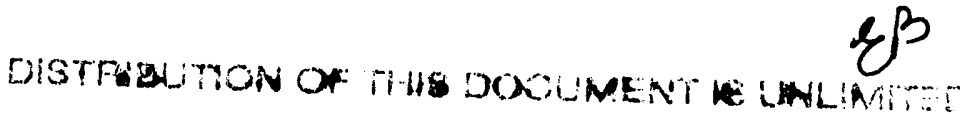




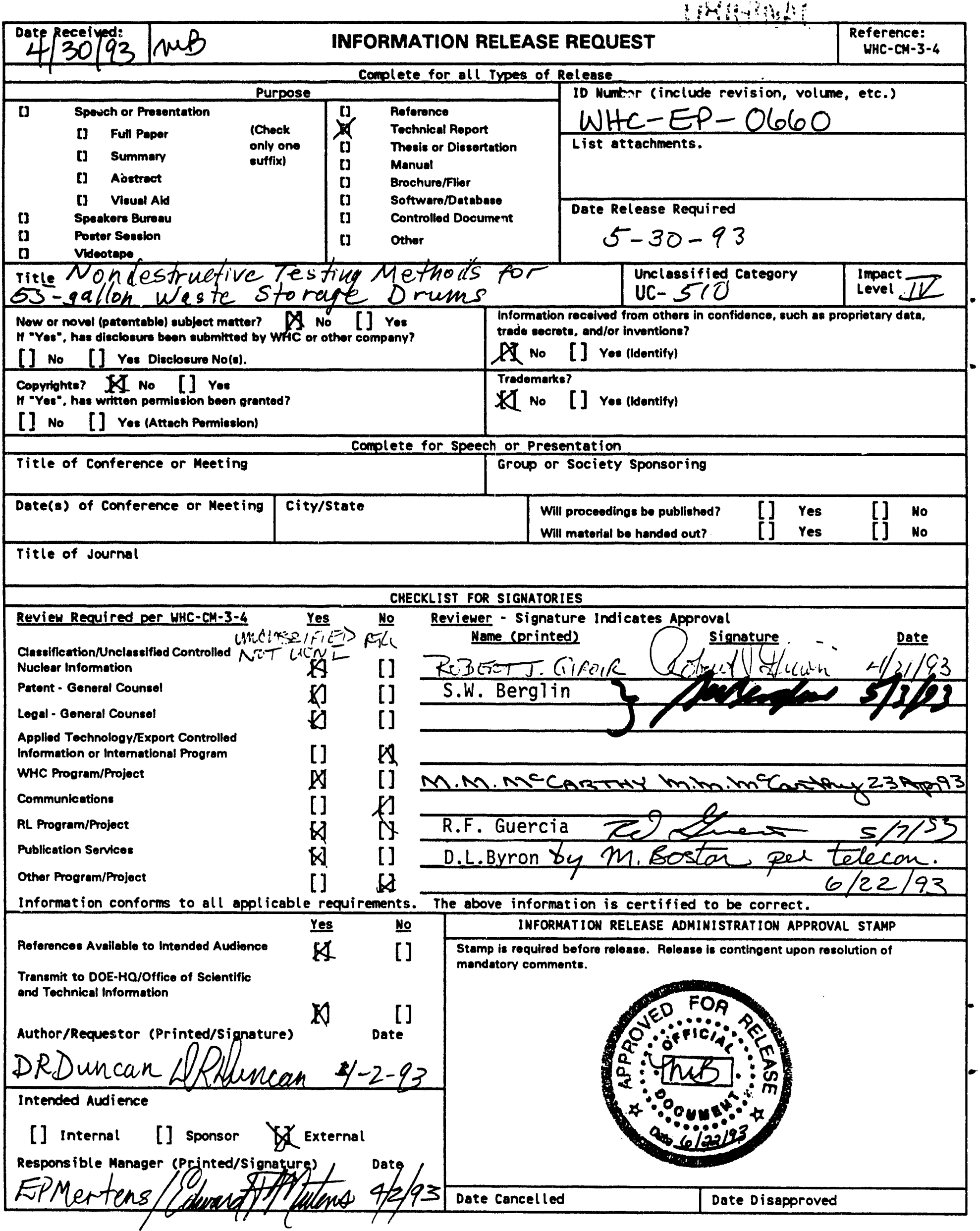


WHC-EP-0660

CONTENTS

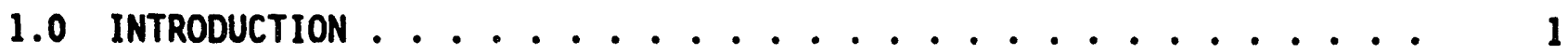

2.0 SURVEYS . . . . . . . . . . . . . . . . . 2

2.1 LITERATURE SURVEY . . . . . . . . . . . . . . . 2

2.2 VISIT TO IDAHO NATIONAL ENGINEERING LABORATORY

RADIOACTIVE WASTE MANAGEMENT COMPLEX ...............

3.0 BRAINSTORMING SESSIONS AND SCOPING ANALYSES ........... 5

3.1 BRAINSTORMING SESSIONS .................. 5

3.1.1 Wall Thickness ................... 6

3.1.2 Pinhole Corrosion ................ 7

3.1.3 Bottom Crimped Joint ................ 7

3.1.4 Screening Techniques................. 7

3.1 .5 Wall Thickness .................... 9

3.1.6 Pinhole Corrosion ............... 9

3.1.7 Bottom Crimped Joint ............... 9

3.1.8 Screening Techniques ................. 9

3.2 SCOPING ANALYSES ..................... . . . . 9

4.0 METHODS DESCRIPTIONS . . . . . . . . . . . . . . . . 10

4.1 MAGNETIC TESTING TECHNIQUES . . . . . . . . . . . . 10

4.2 EDDY CURRENT TECHNIQUES ...................... 11

4.3 SHEAROGRAPHY ...................... 11

4.4 ULTRASONIC TESTING . . . . . . . . . . . . . . . . . . . 12

4.5 RADIOGRAPHIC COMPUTED TOMOGRAPHY . . . . . . . . . . . . . . 13

4.6 THERMOGRAPHY TECHNIQUES ................... . . . 13

4.7 LEAK TESTING WITH ACOUSTIC DETECTION . . . . . . . . . . . . . . 14

5.0 LABORATORY TESTS . . . . . . . . . . . . . . . . . . 14

5.1 TEST DRUM AND OTHER SPECIMENS ................. . . . 14

5.2 THERMOGRAPHY TECHNIQUES ..................... 17

5.3 SHEAROGRAPHY TECHNIQUES ................... 17

5.4 EDDY CURRENT TECHNIQUES ..................... . . . 21

5.5 MAGNETIC FLUX LEAKAGE METHOD . . . . . . . . . . . . . . . 23

6.0 CONCLUSIONS AND RECOMMENDATIONS . . . . . . . . . . . . 29

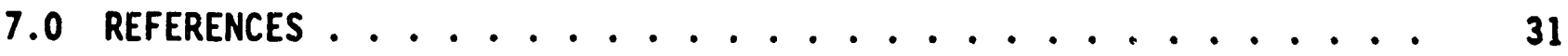

\section{APPENDICES}

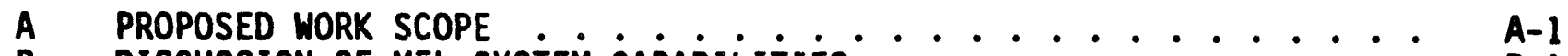

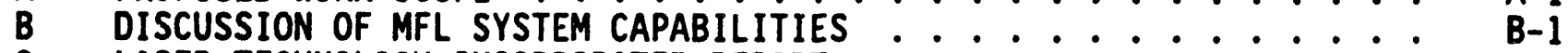

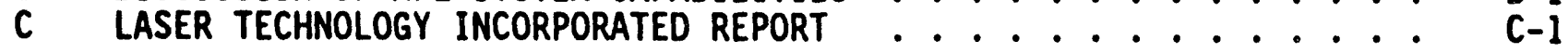




\section{LIST OF FIGURES}

1 Sketch of 55-gal Drum Test Specimen Showing Flaw Sizes, Locations, and Numbering Scheme. . . . . . . . . . . 16

2 Test Specimen Made Using the Lid From a New, Painted 55-gal Drum ..........................

3 Test Specimen Made Using A Plate of Mild Steel to Quantify the Magnetic Flux Leakage Response Signals . . . . . . . . . . . 19

4 Plots Showing Magnetic Flux Leakage . . . . . . . . . . . . 25

5 Maximum Voltage Output From the Magnetic Flux Leakage Probe Versus Depth of Flaws Located on the Back Surface of the Steel Test Plate Shown in Figure 3............... 27

6 Output Voltage Recorded at 0.0005 in. Intervals as the Magnetic Flux Leakage Probe Scanned Each of the Four Lines of Flaws on the Steel Test Plate Shown in Figure 3..............

\section{LIST OF TABLES}

1 Literature Survey Results. . . . . . . . . . . . . . . . 3

2 Shearography Flaw Detection. . . . . . . . . . . . . 21 


\section{LIST OF TERMS}

AE

BAM

CT

DOT

EMAT

ET

FY

INEL

LTI

MFL

NDT

PNL

PT

RTR

RWMC

SWEPP

TBD

TRU

UT

WHC acoustic emissions

Bundesanstalt fuer Materialpruefung

computed tomography

Department of Transportation

electromagnetic acoustic transducer eddy current

fiscal year

Idaho National Engineering Laboratory

Laser Technology, Incorporated

magnetic flux leakage

nondestructive testing

Pacific Northwest Laboratory

liquid penetrant

real-time radiography

Radioactive Waste Management Complex Stored Waste Examination Pilot Plant to be determined

transuranic

ultrasonic testing

Westinghouse Hanford Company 
WHC-EP-0660

This page intentionally left blank. 


\section{EXECUTIVE SUMMARY}

The Westinghouse Hanford Company (WHC) authorized Pacific Northwest Laboratory (PNL) to conduct a feasibility study to identify promising nondestructive testing (NDT) methods for detecting general and localized (both pitting and pinhole) corrosion in the 55-gal drums that are used to store solid waste materials at the Hanford Site. This document presents results obtained during a literature survey, identifies the relevant reference materials that were reviewed, provides a technical description of the methods that were evaluated, describes the laboratory tests that were conducted and their results, identifies the most promising candidate methods along with the rationale for these selections, and includes a work plan for recommended follow-on activities.

From the literature survey, it appears that interest in this application is limited to the nuclear industry because the six most relevant articles all referred to work funded by government agencies responsible for nuclear activities. The primary references from the literature survey described an ultrasonic testing (UT) system used at the Idaho National Engineering Laboratory (INEL) and a real-time radiography and computed tomography (RTR/CT) concept that was the subject of two separate feasibility studies.

Two PNL representatives visited the Stored Waste Examination Pilot Plant (SWEPP) facilities at INEL to observe demonstrations of UT and RTR systems used to inspect 55-gal transuranic (TRU)-waste containers. Waste drums are placed on a rotating platform where UT wall thickness measurements are made at 
eight separate, 360 degree scan paths that are about $1 / 16 \mathrm{in}$. wide. The instrument used is an INEL-modified eight-channel Panametrics UT thickness gauge. This system can detect oxide (corrosion) buildup of 0.01 in. or more and measure wall thinning changes as small as $0.001 \mathrm{in}$. To date, this system has been used to inspect more than 20,000 drums, and the current inspection rate is about 20 min per drum. Operating experience with this system has been relatively good, and the system is regarded as being both rugged and reliable. This system was developed in the early 1980's with an estimated cost of $\$ 200,000$. Current technology, while considerably more costly, could be employed to provide a system with much greater capability and sophistication, particularly in the areas of data acquisition, presentation, and recording.

Brainstorming sessions involving key PNL personnel were conducted to identify concepts and NDT methods for detecting general and localized corrosion. For discussion purposes, this problem was divided into four unique subelements that were addressed separately. These subelements were (1) wall thickness, (2) pinhole corrosion, (3) bottom rolled edge, and (4) overall screening techniques to separate problem drums from nonproblem drums. Numerous NDT techniques were identified for each subelement problem, and these were further refined and prioritized during a subsequent session. Methods considered to merit experimental evaluation included magnetic flux leakage (MFL), eddy current (ET), thermography, shearography, acoustic emission (AE), and RTR/CT.

PNL personnel also visited some of the drum storage sites in the Hanford Site's 200 Areas. These tours were very enlightening because they provided firsthand insight into the nature and constraints associated with NDT. 
Limited stress analysis calculations concluded that the maximum external pressure during drum testing must be limited to $1-2 \mathrm{lb} / \mathrm{in}^{2}$, which corresponds to lid collapse; whereas, the buckling pressure for the shell area was estimated to be about $56 \mathrm{lb} / \mathrm{in}^{2}$. One to two $\mathrm{lb} / \mathrm{in}^{2}$ is thought to be sufficient for leak detection using AE; however, the practical difficulties associated with handling and pressurizing the drums, plus the knowledge that this method offers little promise for detecting incipient leaks, terminated further consideration of the AE method.

This document contains a brief overview and technical description for each of the following NDT methods: (1) magnetic testing techniques, (2) ET techniques, (3) shearography, (4) UT, (5) radiographic CT, (6) thermography, and (7) leak testing with acoustic detection.

Experimental tests were conducted to evaluate the feasibility of the thermography, shearography, ET, and MFL methods. A 55-gal drum test specimen was designed to provide a means for conducting laboratory evaluations of these methods. The simulated corrosion flaws included 25\%, 50\%, and 75\% (of wall) thinned areas in sizes of $1 / 2$ in. by $1 / 2$ in., 1 in. by 1 in., and 2 in. by 2 in. on the inner and outer drum surfaces. Pointed-bottom and flat-bottomed holes 25\%, 50\%, and $75 \%$ through the wall were also fabricated with diameters of 1/32 in., $1 / 16$ in., and $1 / 8$ in. Elongated slots $1 / 4$ in. wide by 3 in. long were then ground $25 \%$ and $50 \%$ through the wall. This test drum was used during both the MFL tests conducted at PNL and the shearography tests conducted under subcontract with Laser Technolegy, Inc. (LTI) in Norristown, Pennsylvania. Three other test specimens were acquired and/or fabricated for evaluating the MFL, ET, and thermography methods. 
The thermography (infrared) response was strongly indicative of surface emissivity variations rather than flaws. Thus, the thermography results were judged to be generally negative because a fairly complex emissivity compensation scheme would be required to reduce emissivity effects to a sufficiently negligible value.

LTI's shearographic experiments were conducted using vacuum, acoustic, thermal, and vibration stressing. The shearography method appears effective for large, deep flaws; marginally effective for small or shallow flaws; and completely ineffective for very small and/or shallow flaws. LTI concluded that implementation of shearography as a production inspection tool would be possible using vibration stressing. LTI recommended further tests using drums with actual corrosion and perhaps simulated contents. If successful, this would be followed by field testing of LTI equipment on actual solid waste storage drums at the Hanford Site. LTI representatives suggested that these drums be inspected with a 60 degree field of view; requiring six images around the circumference at three heights (i.e., 18 images). This should require about 3 min per drum and could possibly be used as a screening tool to segregate potentially flawed drums from unflawed drums.

Both techniques, single frequency and pulsed ET were considered. Laboratory tests using single frequency equipment showed that the ET technique requires an application of a strong magnetic field to the drum to reduce the noise caused by magnetic permeability variations and to allow the ET to penetrate the full wall thickness. A literature search was conducted to 
evaluate the pulsed ET technique, and all of the references found described stainless steel applications. Due to the very successful tests with the MFL method, and its similarity to the ET method, further work on the ET method was discontinued.

The size and shape of distortion patterns in the magnetic flux fields surrounding discontinuities in the 55-gal drum walls are directly related to the geometry of the discontinuity that distorted the magnetic field. A Hall sensor can detect these patterns and generate a voltage proportional to the amount of distortion that occurs in the induced magnetic field when a discontinuity is encountered. An experimental MFL system was designed, fabricated, and tested. This system consisted of a Hall effect sensor to detect small perturbations in magnetic fields along one axis and the electronics for converting these signals into a voltage display on an oscilloscope. The magnet and Hall sensor probe were mounted on a four-wheeled carriage to facilitate scanning across the test specimens.

The MFL method was demonstrated to be very effective in detecting simulated flaws located throughout the wall of the test specimens. Every artificial flaw in the test drum was detected with high reliability and it appeared that the method was also capable of providing a measure of flaw depth as well as overall size and shape. To evaluate this potential, another test specimen was fabricated using a flat steel plate. The plate was precisely machined with notches and flaws of varying sizes and shapes. Tests were conducted to evaluate the capability of this method for providing flaw characterization information. All of the tests conducted to date, with the MFL method, have demonstrated considerable promise for this application. 
It appears that an RTR/CT system could be developed to provide an effective inspection; however, the cost and complexity of such a system, plus a relatively slow inspection rate, limits the attractiveness of this method. Most of the other NDT methods considered are not promising candidates for this application due to inherent technical limitations, incompatibility with field implementation considerations, or both.

Based on this Phase I feasibility study, we concluded that the inspection of 55-gal waste storage drums represents a formidable technical problem. We also concluded that the MFL method offers the most viable solution to this inspection problem. The shearography method, while not capable of detecting small or medium sized flaws, is potentially able to serve as a screening test that could be used to segregate drums with gross corrosion from sound drums.

On the basis of the work described in this document, we recommended that additional development and evaluation of the MFL method be authorized. An initial FY 93 budget request of $\$ 100 \mathrm{~K}$ was submitted to WHC to complete the Phase I work (including report issuance), complete most of the proposed Phase II work, and initiate the Phase III work.

It is further recommended that, if additional funds can be made available, a subcontract should be placed with LTI for further testing of the shearography method using drums with actual corrosion and simulated contents. If successful, field testing of the LTI shearography equipment on actual solid waste storage drums at the Hanford Site should be considered if a gross screening method is needed. 


\section{NONDESTRUCTIVE TESTING METHODS FOR \\ 55-GALLON, HASTE STORAGE DRUNS \\ PHASE I - FEASIBILITY STUDY}

\subsection{INTRODUCTION}

The Westinghouse Hanford Company (WHC) authorized Pacific Northwest Laboratory (PNL) to conduct a feasibility study to identify promising nondestructive testing (NDT) methods for detecting general and localized (both pitting and pinhole) corrosion in the 55-gal drums that are used to store solid waste materials at Hanford. This study was initiated in late fiscal year (FY) 1991 and completed in early FY 93. The need for a rapid means of assessing container wall integrity is illustrated by the pinhole corrosion failure of several dozen drums of 183-H Basin sludge waste in 1990. Conventional hand-held ultrasonic probes are slow, and in the case of the 183-H Basin drums, proved ineffective in accurately detecting corrosion on the drum interior surfaces. The radiation readings at the surface of these drums is less than $200 \mathrm{mR} / \mathrm{h}$.

Key drum inspection requirements and criteria initially provided by WHC were as follows:

1. The specified wall thicknesses are:

- Department of Transportation (DOT)-Type 17-H drums--0.050 in. (nominal) and 0.043 in. (minimum)

- DOT-Type 17-C drums--0.060 in. (nominal) and $0.053 \mathrm{in}$. (minimum)

NOTE: Minimums are per DOT specification for the steel sheet before drum manufacture.

2. The inner and/or outer drum surfaces may be galvanized, painted, and/or covered with rust.

3. Wall thickness measurements are needed for the drum shell and top cover with an accuracy of \pm 0.005 in.

4. The minimum detectable area of corrosion is $0.01 \mathrm{in}^{2}$ (i.e., $0.1 \mathrm{in}$. $x 0.1$ in.).

5. The goal is to inspect an entire drum in 15 mins or less, drum wall thickness must be measured in real time, and the equipment must function in the field (i.e., in a burial trench). 
Desirable inspection requirements and criteria include the following.

1. The capability to inspect the top and bottom rolled edges of the drum

2. Automated or semi-automated data reduction and readout

3. A noncontacting probe and sensor system

4. The capability to inspect the drum bottom while the drum is upright.

This document presents the results obtained during the literature survey, identifies (in bibliographic form) the relevant reference materials that were reviewed, provides a technical description of the methods that were evaluated, describes the laboratory tests that were conducted and the results obtained, identifies the most promising candidate methods along with the rationale for these selections, and includes a work plan for the recommended follow-on Phase II task.

\subsection{SURVEYS (LITERATURE, MARKET, AND IDAHO MATIONAL ENGINEERING LABORATORY VISIT)}

\subsection{LITERATURE SURVEY}

An initial literature survey at the PNL library resulted in four applicable reports, and personal contact with other researchers yielded two more. Due to the limited success of the search, the survey was expanded to the past 20 years and included other thin section applications.

Unfortunately, this did not result in any additional relevant references. It appears that interest in this application is limited to the nuclear industry. All six articles referred to work funded by government agencies responsible for nuclear establishments. These six, plus other relevant references, are listed in the reference section of this document.

The search protocol shown in Table 1 produced a total of 54 unique abstracts. These were all reviewed with the results as described above. The relevant reports described work performed at Idaho National Engineering Laboratory (INEL), Bundesanstalt fuer Materialpruefung (BAM), and Bio-Imaging Research, Inc. (Barna, Brown, and Anderson 1983; Bishoff 1982; Hinckley 1982; Cook et al. 1984; Bernardi 1990; Kettschau, Reimers, and Goebbles 1985). These reports discuss real-time radiography (RTR), ultrasonic testing (UT), and computed tomography (CT). The only $100 \%$ inspection method is RTR. This system, however, is primarily designed for examining the contents of the drum, a) though mention is made of the ease with which free liquids may be detected (Barna, Brown, and Anderson 1983). 
Table 1. Literature Survey Results.

\begin{tabular}{|l|l|l|}
\hline \multicolumn{1}{|c|}{ Set } & \multicolumn{1}{|c|}{ Items } & \multicolumn{1}{c|}{ Description } \\
\hline S1 & 107148 & $\begin{array}{l}\text { Tomograph? or X-ray or Radiograph? Or U1traso? or } \\
\text { ET or Cat }\end{array}$ \\
\hline S2 & 2617874 & $\begin{array}{l}\text { Measurement? or Inspect? or Determin? or Examin? } \\
\text { or Imaging or NDE or NDT or testing or thickness }\end{array}$ \\
\hline S3 & 623 & Corro?(5N) Steel (5n) (drum or barrel or contain?) \\
\hline S4 & 7 & S1, S2, and S3 \\
\hline S5 & 194 & 55() Gallon(5n) (drum? or barrel? or contain?) \\
\hline S6 & 3 & S1, S2, and S5 \\
\hline S7 & 510337 & Drum? or Barrel? or Contain? \\
\hline S8 & 3885 & S7, S1, and S2 \\
\hline S9 & 169 & Corro and S8 \\
\hline S10 & 56 & Steel and S9 \\
\hline S11 & 5952 & Steel (5N) (Drum? or Barrel? or Contain?) \\
\hline S12 & 56 & S1, S2, and S10 \\
\hline ? C 4t6+12+10 \\
\hline S14 \\
\hline
\end{tabular}

The UT system reported by INEL consists of an eight-channel instrument using $10-\mathrm{MHz}$ focused transducers at eight locations; two on the bottom, two on the bottom rolled edge, three on the sidewall just below the hoops, and one near the edge of the cover (Cook et al. 1984). The drum is rotated in the almost upright position, thus achieving a 360 degree scan at the eight positions described. 
The reports on $C T$ include evaluations of this technology for detection of free liquids in 55-gal drums (Bernardi 1990) and a means for evaluating the integrity of the drum itself (Kettschau, Reimers, and Goebbles 1985). The former article describes a feasibility study using a CT scanner installed at NASA's Marshall space flight center and a surrogate barrel of solidified waste. This system uses a combination of RTR and CT to:

- Identify free liquid at any location within the container

- Quantify percent volume of material states (e.g., liquid) with millimeter resolution

- Quantify the specific gravity of materials in the container (e.g., concrete, sludge, salt water, water, etc.), with nearly $1 \%$ resolution

- Identify unknown contents within containers

- Discover breaches of container inner liners.

The paper concludes with the comment that a mobile, trailer-mounted unit can be built that would be capable of a four to eight barrels per hour throughput using current technology.

The other CT report specifically targets the application of establishing the integrity of the container itself (Kettschau, Reimers, and Goebbles 1985). This study concluded that CT could indeed detect corrosion effects on the inside of the container.

\subsection{VISIT TO IDAHO MATIONAL ENGINEERING LABORATORY RADIOACTIVE WASTE MANAGEMENT COMPLEX}

Two PNL representatives (B. P. Hildebrand and J. C. Spanner) visited the INEL and Radioactive Waste Management Complex (RWMC) on October 30, 1991 to observe the Stored Waste Examination Pilot Plant (SWEPP) facilities. The purpose of this trip was to observe demonstrations of the UT and RTR systems used for inspecting 55-gal transuranic (TRU)-waste containers. An overview tour of most of the RWMC facilities was also included in the itinerary for this 1-day visit that was coordinated by RWMC's Mr. Jerry Gilman.

The RWMC operation is involved in a pilot program to ship TRU-waste to the permanent storage facility being built in New Mexico. The SWEPP facilities are set up to process TRU-waste containers (i.e., 55-gal drums) on a production scale. Two of the currently most active waste container storage facilities are enclosed in large inflatable "bubble" tents. Additional RWMC factlities include a large area of waste storage zones (some above and some below ground level); most of which have been covered or backfilled with soil. Barrels of radioactive waste are also stored on uncovered concrete pads. Numerous below ground waste storage vaults are located in the multi-acre RWMC storage area, and sampling wells are used to monitor the subsurface movement of waste radioactive materials down to $600 \mathrm{ft}$. 
The major focus of this visit was to observe the ultrasonic and radiographic systems used at SWEPP to monitor the contents and integrity of 55-gal drums. When the drums enter the SWEPP, they are first placed in a containment tank where the 1 id is remotely pierced and a vent with a carbon filter is inserted. They are then weighed, measured, and examined using a RTR system and a neutron activation and scanning system. A video tape was used to illustrate and demonstrate the capabilities of the RTR system. The drum is then placed on a rotating platform where UT wall thickness measurements are made at eight separate, 360 degree scan paths (one on the top lid, two on the bottom 1id, three on the drum shell, and two more as close to the bottom crimp joint as possible). The instrument used is an INEL-modified, eight-channel Panametrics UT thickness gauge. This system can detect an oxide (corrosion) buildup of 0.010 in. or more and measure wall thinning changies as small as 0.001 in. The overall accuracy and reproducibility of the system is in the range of $\pm 5 \%$.

To date, this UT system has been used to inspect more than 20,000 drums, and the total e? apsed inspection time is currently about 20 min per drum. This includes loading and unloading the drum, one $360^{\circ}$ UT inspection, and some data verification using a hand-held UT thickness gauge, if necessary. Discussions with the SWEPP equipment supervisor indicated that the operating experience with this system has been very good since initial debugging, and the system is regarded as being both rugged and reliable. The system uses focused search units operating at $10 \mathrm{MHz}$ with water coupling, and a scanning speed of about $1 \mathrm{in} / \mathrm{s}$. The "bubbler" technique that is used reduces water consumption to a minimum. Because no additives are used in the couplant, there are no significant waste disposal problems. The water path length is limited (by design) to $\pm 0.060 \mathrm{in}$. and the diameter of the beam at the focal point is about 0.050 in. The system can measure steel wall thicknesses over a range from $0.02 \mathrm{in}$. to 0.120 in. using multiple back reflections.

It was indicated that the total cost of this system was over $\$ 200,000$ (development plus capital costs) in the early 1980's. Current technology, while considerably more costly, could be employed to provide a system with much greater capability and sophistication; especially in the areas of data acquisition, presentation, and recording.

\subsection{BRAINSTORMING SESSIONS AND SCOPING ANALYSES}

\subsection{BRAINSTORAING SESSIONS}

A brainstorming session was held July 31, 1991, to develop techniques and concepts for detecting general and localized corrosion. PNL participants included D. M. Boyd, K. C. Davis, B. P. Hildebrand, R. L. Hockey, G. J. Posakony, and J. C. Spanner. D. R. Duncan (WHC) summarized the history and status of this problem at the Hanford Site and highlighted the key requirements, parameters, and constraints. 
For discussion purposes, this problem was initially subdivided into subelements as follows (1) gross wall thickness, (2) top cover thickness, (3) pinhole corrosion, (4) bottom cover inspection, (5) surface scanning, (6) content analysis/liquid detection, (7) bottom rolled edge, and (8) drum screening and segregation techniques. These seven problem subelements and their interrelationships were then addressed. Because solutions to some of the subelements provide solutions to one or more other subelements (e.g., techniques for measuring drum shell thickness are probably also applicabie for measuring the thickness of top and bottom covers), only the four unique subelements were specifically addressed.

The following four key subelements were addressed in sequence (1) wall thickness, (2) pinhole corrosion, (3) bottom rolled edge, and (4) overall screening techniques to differentiate or separate problem drums from nonproblem drums. The methods and techniques suggested for each problem subelement are listed below. Descriptions of the methods considered to offer promise for these applications are provided in the next section.

\subsubsection{Wall Thickness}

1. CT

2. RTR

3. Electromagnetic acoustic transducer (EMAT)

4. ET

5. MFL

6. Ultrasonic longitudinal waves

7. Uitrasonic Lamb waves

8. Optical holography

9. Thermal and infrared response

10. Shearography

11. Helium leak testing

12. Acoustic emission (AE) (vacuum or thermal stresses)

13. Vibro-holography

14. Mechanical " $Q$ " (physical strength modulus)

15. Localized (spot) heating $\left(\approx 5^{\circ} \mathrm{F}\right)$ with a laser, combined with ET probe to detect anomalies. 


\subsubsection{Pinhole Corrosion}

1. Electro-chemical corrosion monitor

2. AE (thermal or vacuum stresses)

3. Radiographic CT

4. Liquid penetrant (PT) immersion, drain, and observe

5. Magneto-optics

6. Optical Tuminescence

7. ET

8. MFL

9. Infrared hot spot detection

10. Statistics (i.e., reliability of sampling scheme)

11. Leak testing (helium, AE, PT)

12. Localized (spot) heating $\left(\approx 5^{\circ} \mathrm{F}\right)$ with a laser, combined with ET probe to detect anomalies.

\subsubsection{Bottom Crimped Joint}

1. Radiography (film or real-time)

2. ET with magnetic saturation

3. MFL

4. Radiographic CT

5. Mechanical resonance

6. Optical holography

7. UT thickness of joint (parallel and perpendicular to shell)

8. Overpack (i.e., repackage in oversized drum).

\subsubsection{Screening Techniques}

(To identify drums requiring more detailed inspection.)

1. Statistics

2. Content assessment

3. Weight of drum

4. Color of drum surface

3. Temperature of drum surface

6. Radiation level at drum surface

7. Expose drum to pressure or vacuum

8. Sniff test

9. Drum manufacturer's track record

10. Thermal response 
11. Good and bad material

12. Steel supplier records by heat

13. Evidence of leakage (i.e., optical, luminescence, etc.)

14. Corrosion monitoring.

It was noted that provisions for pressure relief are provided for some drums, but not for others. Therefore, this fitting (where available) could possibly be used for pressurizing or depressurizing selected drums. However, Duncan indicated that there would probably be some reluctance to impose stresses on drums whose iritegrity was unknown. Discussions were also conducted regarding the possibility and desirability of cleaning the drum surfaces viagrit blasting. Again, there could be reluctance to permitting surface conditioning before inspection. At the conclusion of this meeting, it was evident that inspection of $55-\mathrm{gal}$, solid waste storage drums represents a formidable technical problem. There are no obvious or simple solutions, and in fact the problem may not be solvable within the present constraints (e.g., accessibility, desired inspection speed and accuracy, budget limitations, etc.).

Subsequent to this meeting, Duncan arranged for Hildebrand and Spanner to visit drum storage sites in the Hanford Site 200 Areas. This tour was very enlightening because it provided firsthand insight into the nature and actual constraints associated with this problem. In general, the solid waste storage drums are banded in groups of four which are then stacked two to four barrels high, with pallets or sheets of plywood between each layer. One prevalent storage configuration was four-barrel groups stacked four high with interleaving pallets located in a series of Butler (prefabricated metal) buildings. It appeared that the employee who periodically visually inspects the drums stored in and near the Butler building complex might be even more effective if a portable ultrasonic gage (T-Gage) were provided so the thickness of selected areas on certain drums could be monitored and tracked.

The contents of most drums are "bagged" in a relatively thin polyethylene bag that is sufficiently longer than the height of the drum to permit folding over and taping the opening in a "horsetail" configuration. Some drums also contain a $0.090 \mathrm{in}$. thick polyethylene liner.

In mid-September, a smaller PNL group met to (1) consider the overall inspection problem, (2) screen and prioritize the methods and techniques identified during the earlier brainstorming session, and (3) develop a course of action for completing the FY 91 activities and initiating the FY 92 work. This group consisted of J. S. Hartman, B. P. Hildebrand, R. L. Hockey, and
J. C. Spanner.

During this session, the collective engineering judgement of the four attendees was used to ident ify the most promising methods for each key problem subelement and to eliminate those regarded as offering little or no practical applicability. The results of this process are as follows. 


\subsubsection{Wall Thickness (Prioritized)}

1. Electromagnetic techniques involving magnetic saturation and flux leakage detection using ET or Hall effect sensors

2. Shearography

3. UT-longitudinal waves involving an EMAT techniques

4. RTR/CT

5. Thermal response involving localized (spot) heating $\left(\approx 5^{\circ} \mathrm{F}\right.$ ) with a laser, combined with ET probe to detect anomalies.

\subsubsection{Pinhole Corrosion (Prioritized)}

1. MFL techniques

2. ET

3. $\mathrm{RT} / \mathrm{CT}$

4. Magneto-optics/magnetic particle

5. Leak testing (pressurize, plus AE or PT detection)

6. Thermal response (i.e., hot spot detection)

7. Optical luminescence.

\subsubsection{Bottom Crimped Joint (Prioritized)}

1. UT thickness measurements (parallel and perpendicular to shell)

2. RTR/CT

3. Radiography (real time or film)

4. Fiux leakage (magnetic saturation with ET detection)

\subsubsection{Screening Techniques}

(To identify drums requiring more detailed inspection.)

1. Visual appearance (stains, color, texture, and evidence of leakage.)

2. Content assessment via RTR

3. Track record of packaging source (source, date, and known problems.)

4. Statistics/correlations

5. Drum manufacturer's lot.

\subsection{SCOPING NMALYSS}

Limited stress analysis calculations were performed to estimate the external pressure that could be applied to a drum without deformation. The maximum external pressure the lid can tolerate was estimated to be 1 to 2 Ib/in ${ }^{2}$; whereas, the buckling pressure for the shell area was estimated to be about $56 \mathrm{lb} / \mathrm{in}^{2}$. Thus, the maximum pressure to which a drum can be subjected will be 1 imited by lid collapse (i.e., 1 to $21 \mathrm{~b} / \mathrm{in}^{2}$ ). 
A PNL AE specialist was then asked to estimate the size of a leak that should be detectable by $A E$ for a barrel externally pressurized to $1 \mathrm{lb} / \mathrm{in}^{2}$. Previous leak testing results, combined with a rough calculation of the flowrate through various sized leaks, indicated that leaking pinholes of about $0.01 \mathrm{in}$. diameter should be detectabie for a drum pressurized to about 1 $1 \mathrm{~b} / \mathrm{in}^{2}$. While interesting, these estimates are probably of limited value, in the context of this problem, because the practical difficulties associated with handling and pressurizing drums and with the uncertainties of leak detection techniques limit the attractiveness of this approach. Furthermore, while this concept might be further developed to provide the needed leak detection capability, it offers little promise as a method for detecting corrosion thinned areas that have not yet leaked.

\subsection{METHODS DESCRIPTIONS}

The following paragraphs provide a brief overview for each of the NDT methods/concepts that appear to offer the most promise at this time. These overviews are provided to introduce the non-NDT specialist to the underlying physical principles for each method, to provide some insight as to the capabilities and limitations of the various methods, and to provide specific information on how these methods might be applied for measuring drum wall thickness to detect general or localized corrosion. More quantitative insight as to the actual capabilities of selected methods is provided in the section describing the results of the laboratory tests that have been performed.

\subsection{MAGNETIC TESTING TECHNIQUES}

Magnetic testing broadly comprises all methods in which magnetic fields play an essential role. One specific type of magnetic testing, commonly referred to as MFL, uses leakage of magnetic field lines to indicate discontinuities in material properties. When a sample is tested for flux leakage, a relatively strong and uniform magnetic field is applied to the sample. Areas within the material containing voids, impurities, or cracks will perturb the otherwise uniform applied field. Under certain conditions, flawed areas are detected by mapping field lines at the surface. Flawed regions are expected to have stronger magnetic field lines protruding from the surface over the flaw. This method has also been used to determine the type and size of flaws.

It is a familiar phenomenon that some ferromagnetic materials, when magnetized by an external field, do not return to a completely unmagnetized state when removed from that field. This is expected to be the case for the steels used to manufacture 55-gal drums. If a drum were subjected to a uniform magnetic field of sufficient strength to obtain saturation on a hysteresis loop, when the field is removed, the residual magnetic field can be mapped for anomalies that may be present due to various types of corrosion, including pinholes. This technique requires a probe that is very sensitive to small changes in magnetic field. A Hall effect sensor is commonly used to measure field variations of this magnitude. This technique employs the same principles that are used to make audio recordings on magnetic tape. 
For $100 \%$ inspection of the drum surface in a reasonable time, several sensors must be arranged into an array and monitored simultaneousiy. Recordings can then be processed to form a two-dimensional image of the drum surface, and images of this type may be rapidly interpreted by an operator. These images can also be stored electronically in digital form for comparison with similar scans performed at a later date to determine if the corrosion process is advancing with time.

\subsection{EDDY CURRENT TECHNIQUES}

ET is based on the principles of electromagnetic induction and are used to identify or differentiate a wide variety of physical, structural, and metallurgical conditions in electrically conductive parts. In ET inspection, the ETs create their own electromagnetic field, which may be sensed either through the effects of the field on the primary exciting coil or by means of an independent sensor. Eddy current measurements are sensitive to only two physical parameters (1) effective electrical conductivity and (2) magnetic permeability. For nonferromagnetic materials, recorded signal variations are due to conductivity changes, but it may be difficult to separate a conductivity change from a permeability change for ferromagnetic materials. A static (direct-current) magnetic field is often applied to virtually eliminate the magnetic effects resulting from permeability of the material being inspected.

In the case of a 55-gal waste drum, a strong magnetic field is necessary to magnetically saturate the steel and thus prevent permeability effects from overshadowing conductivity effects. In sufficient quantities, most forms of corrosion would be detectable due to the conductivity change that results from oxidation. An oxide exhibits a different conductivity than the surrounding unoxidized material. The gas pipeline industry has successfully used this technology for detecting and determining the extent of corrosion in stee 1 pipelines when corrosion is $20 \%$ through-wall or greater.

A void would exhibit a much smaller conductivity than the surrounding metal and should be relatively easy to detect using ET techniques. However, because pinholes are very small compared to most eddy current probes, a special probe array is necessary to adequately examine the surface of a drum in an acceptable time period.

\subsection{SHEAROGRAPHY}

Of the optical methods, shearography (Hung 1989) appears to hold the greatest promise for this application. Shearography is global, in that a large area is surveyed, in contrast to methods that use a smali probe to scan over the area. Optical speckle is the underlying principle upon which this method is based. When an object is illuminated with a laser, it has a speckled appearance, and the speckles appear to move and twinkle when the eye is moved. 
Shearography takes advantage of the speckle effect. A video camera with attached lens records the speckle pattern on the 55-gal drum. In ordinary speckle photography, the drum is then stressed by a heat pulse or a small pressure differential, and a second speckle pattern is recorded. This second pattern will be slightly different because those points on the drum that moved under stress produce a local shift in speckle. If the two video frames are subtracted, those speckles that did not shift will cancel out leaving visible only the regions where the subtraction is not perfect. Thus, a weak spot on the drum that deforms under stress will show up as a brighter area.

Unfortunately, this simple technique does not respond to pure out-ofplane displacement. Thus, only in-plane displacements are easily measured. Shearography remedies this problem by inserting a wedge over one half of the camera lens. Now, the speckle pattern is made up of the coherent sum of two sheared patterns. When the drum is deformed and the second pattern is subtracted from the first, the result is a fringe pattern representing a change in slope or strain. Thus, even pure out-of-plane deflection will be visible. Shearography can map changes on the order of 0.1 microstrain at video frame rates.

A shearographic system for barrel inspection might consist of one or more lasers, video camera, and associated electronics. The light from two lasers could be split into two or more beams to illuminate all surfaces of the drum at once. By means of mirrors, or several (4 or 5) cameras, shearographic images of all surfaces could also be recorded.

For this application, a drum is placed on a fixture allowing visibility of all surfaces. After allowing the drum to stabilize for a few minutes, the cameras record an image. Then, a bank of heat lamps is turned on and the camera started. As the drum wall heats up, successive video frames record shearograms as the drum swells (note that the temperature increase is very small and the swelling is minuscule). The computer subtracts each frame from the initial frame, and displays the results in real time. A weak spot expands faster than the surrounding material and will become visible as a compact set of interference fringes.

A complete test would take only a few minutes; the actual heating cycle perhaps only a few seconds. Stressing by applying vacuum, pressure, or vibration could be used if heating is not appropriate. However, it is thought that heat stress would be the easiest, safest, and most effective. This method may not detect corrosion at the bottom rolled seam because of the rigidity of the seam. However, this could be experimentally evaluated.

\subsection{ULTRASONIC TESTING}

UT is a well established technique for measuring the thickness of materials and for finding and sizing flaws. In this method, a pulsed ultrasonic beam is projected into the material, and the echo from the back surface is recorded. The time of flight of the pulse can be related to the thickness of the material if the velocity of propagation is known. This method requires a small diameter beam to detect small anomalies, so a scanning system is required. This can be a simple drum rotation turntable which rotates the drum beneath the ultrasonic search unit. Full 100\% coverage, 
therefore, requires long scanning times. A system in operation at INEL circumvented this problem by scanning only in those regions with the highest (presumed) susceptibility to corrosion (Cook et al. 1984). Eight thin tracks were scanned; one track just below each of the three hoops, one track just above the hottom, one track on the bottom cover near the outside edge, two more on thu bottom cover, and one on the top cover. Thus, the possibility of missing a corrosion area, especially a pit or pinhole, is substantial.

\subsection{RADIOGRAPHIC COMPUTED TOMOGRAPHY}

CT is a relatively new technique for producing high-resolution images of the cross section of an object. The first, and most successful, application for this technology has been for medical diagnosis. Recent developments have extended its use to inspection of engineering structures, such as rocket motors, wooden power poles, and jet engine components. DOE has recently sponsored work in this area for the inspection of solidified low-level waste containers to ascertain the presence of free liquids (Bernardi 1990). The German government funded BAM to evaluate CT for container integrity verification (Kettschau, Reimers, and Goebbles 1985). They concluded that CT could provide such assurance.

In contrast to conventional radiography, where the image represents a projection or shadow of the object onto the film plane, CT provides a detailed, focused image of a slice of the object. This is achieved by shining a fan-shaped $X$-ray beam through the object and detecting its projection by a linear array of detectors. The object is then rotated and many such projections are recorded. A computer algorithm then compares these data to data that would have been obtained if a simulated object were present. By an iterative process, the simulated object is altered to produce data more similar to the measured data. Eventually the model converges to the true object. Excellent resolution in both material density and position are possible. Thus, an excellent image of the object in the plane of the fan beam is obtained.

The latest generation of CT machines produced by LTI extends the technique to a full three dimensions. This is done by using a cone beam of $X$-ray energy to $i l l$ uminate the complete object. A two-dimensional array of detectors on the other side records the projection, as would a piece of $X-r$ ay film or RTR system. The object is once again rotated and many such projections are stored. By a similar iteration process, a three-dimensional image is generated. Because an RTR machine produces fuil $x$-ray projections in real time, it is possible to add the software like the program produced by Bio-Imaging Research, Inc. to provide CT images as well. However, in general, the resolution will not be as good as that produced by a machine designed specifically for $\mathrm{CT}$.

\subsection{THERMOGRAPHY TECHNIQUES}

Thermal imaging is gaining acceptance as an NDT method for detecting debonds in composites or defects in thin steel plates (Bruno 1989). This method is based on the premise that the surface temperature of a plate sample will depend on its thickness due to a difference in thermal conductivity. 
Thus, if an object is subjected to heat stress, an infrared camera will reveal differences in surface temperature. Unfortunately, the emissivity of the surface may mask the variations due to thermal conductivity. However, this may be obviated by recording the image before heat stress is applied and subtracting it from succeeding images (Kuo et al. 1989). With modern cameras and computers, this can be done in real time, thus allowing the operator to observe defects in the form of hot spots.

This method would require the same physical set up as that used for shearography. It must also be possible to perform both tests simultaneousiy to improve the probability of detection of thin spots.

\subsection{LEAK TESTING NITH ACOUSTIC DETECTION}

Leak testing with acoustic detection may be useful for detecting pinhole leaks and, depending on the applied stress, near through-wall corrosion which might be breached by the stress. In tinis method, a pressure chamber would be built to surround the drum. Because the lid may not be sealed, the top of the chamber would clamp to the drum near its top, so that only the side and bottom of the drum experience pressure. The chamber is then pressurized and acoustic microphones listen for the sound of air being forced through leaks into the drum.

Pressure, instead of vacuum, is chosen so that the contents of the drum are not released into the chamber in case a leak is present. Depending on the allowable pressure, this test may also detect preleak conditions by breaking through regions where corrosion is almost through-wall.

Limited analyses were performed to (1) determine the approximate pressure that could be applied to a drum without deformation and (2) assess the feasibility of detecting small leaks in drums subjected to a specific external pressure using $A E$ techniques. The stress analysis results indicated that the drum 1 id would deform at pressures of 1 to $21 \mathrm{~b} / \mathrm{in}^{2}$, and the shell area would buckle at about $56 \mathrm{lb} / \mathrm{in}^{2}$. With these results, an AE specialist estimated that a 0.01 in. diameter hole could probiily be detected by $A E$ at a differential pressure of $1 \mathrm{lb} / \mathrm{in}^{2}$. These results were encouraging except that this technique would only detect existing leaks (or areas on the verge of leaking) but would not be useful for detecting future leak sites and/or general corrosion.

\subsection{LABORATORY TESTS}

\subsection{TEST DRUM AND OTHER SPECIMENS}

A 55-gal drum test specimen was designed to provide a means for conducting uniform laboratory evaluations of the more promising methods. After the test drum design was provided to WHC for review and their comments 
were incorporated, a new DOT-Type 17-C drum was procured and provided to the PNL millwright shop. The nominal wall thickness on this test drum was measured to be 0.052 in. compared to the 0.060 in. nominal ( 0.053 in. minimum) wall thickness usually specified for DOT-Type 17-C drums.

The simulated corrosion flaws were fabricated as shown in Figure 1, using hand-held grinding and drilling equipment. A high-resolution, ultrasonic thickness measuring instrument was used during the grinding operation to monitor the amount of metal removed. Mechanical depth gauges were used to measure the depth of the part-through drilied holes. Following fabrication of the test drum, an NDT laboratory technician verified the depth and sizes of the simulated flaws using the same instruments and fixtures used during flaw fabrication.

The simulated corrosion flaws included $25 \%, 50 \%$, and $75 \%$ (of wall) thinned areas in overall sizes of $1 / 2$ in. by $1 / 2$ in., 1 in. by 1 in., and 2 in. by $2 \mathrm{in}$. on the inner and outer surfaces of the drum. Pointed-bottom and flat-bottomed holes $25 \%, 50 \%$, and $75 \%$ through the wall were al so fabricated with diameters of $1 / 32 \mathrm{in.}, 1 / 16 \mathrm{in.}$, and $1 / 8 \mathrm{in}$. Elongated slots that were $1 / 4 \mathrm{in}$. wide and $3 \mathrm{in}$. long were also ground $25 \%$ and $50 \%$ through the wall.

After fabrication and verification, the test drum was used to obtain some of the MFL measurements described later in this section. The drum was then encased in an 85-gal overpack barrel and shipped to Laser Technology, Inc. (LTI) in Norristown, Pennsylvania, where shearographic response measurements were performed under a subcontract to PNL. Upon completion of the shearography experiments, the test drum was returned to PNL for use during subsequent phases of this project.

Another test specimen was fabricated to facilitate the initial experiments conducted with the magnetic flux leakage (MFL) technique. This specimen was made using the top cover from a new, painted 55-gal drum. Notches were machined into the top and bottom surfaces of the lid to provide flaws of known size for determining the MFL response to notches with various widths and depths. A sketch of this test specimen is shown in Figure 2 . A plastic guide rail was attached to this specimen to facilitate moying the MFL probe across the notches in a repeatable manner. This was important because the hand-held probe needed to pass over the notches at the same location to ensure reproducible and reliable results.

To circumvent the difficulties associated with fabricating and measuring artificial flaws on the curved sides of a 55-gal drum, a third test specimen was fabricated using a flat plate of mild steel that was 10.5 in. by 19 in. by $0.0625 \mathrm{in}$. thick. This specimen contained ball-milled (i.e., round bottomed) notches, end-milled (i.e., flat bottomed) notches, and part-and through-wall holes as shown in Figure 3 . This plate was designed to be mounted on a computer-controlled scanning mechanism so that both the location and the motion of the MFL probe could be controlled during scanning of the simulated flaws available in this test specimen. These flaws were specified with a fabrication accuracy of \pm 0.0005 in. to aid in quantifying the precise response of the MFL method. 
Figure 1. Sketch of 55-gal Drum Test Specimen Showing Flaw Sizes, Locations, and Numbering Scheme.

\begin{tabular}{|c|}
\hline 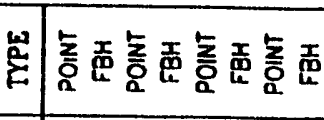 \\
\hline 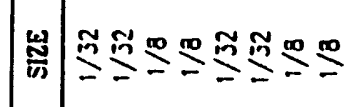 \\
\hline 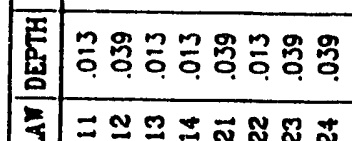 \\
\hline
\end{tabular}

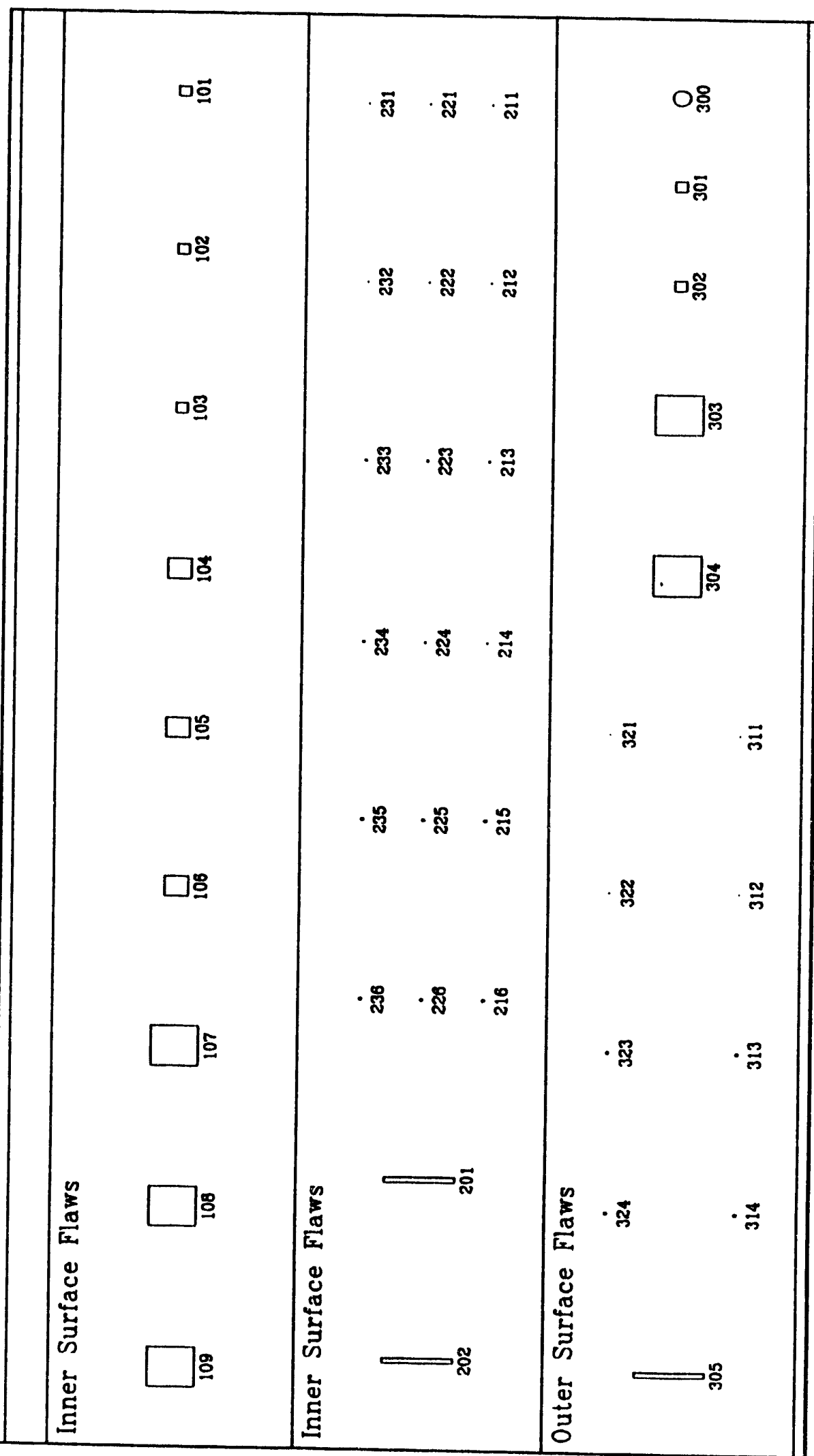


For the thermography tests, another test specimen was prepared using an old, rusty, end-cover from a 30-gallon drum. This specimen contained throughand part-through drilled holes, grourit gouges, and a polished area. It was also used for the initial ET tests, ano a "quick-and-dirty" shearography experiment at PNL that was not successful.

\subsection{THERHOGRAPHY TECHIQUES}

A laboratory setup was assembled to conduct experimental evaluations of the thermography method. The experimental system consisted of a large heat lamp, an infrared camera, and test specimens to simulate corrosion-affected material. The simulated corrosion specimens were prepared with 1-mm diameter drilled holes (through and partly through-wal1), ground gouges, and a large polished area. These samples were tested by actuating the heat lamp while observing the thermal response with an infrared camera. Images were captured on digital frame-grabbers and compared with a reference image obtained before actuating the heat source.

The infrared response was strongly indicative of surface emissivity variations rather than the flaws of interest. Thus, the thermography technique results were judged to be generally negative because it was evident that a fairly complex emissivity compensation scheme would be required to reduce the emissivity effects to a sufficiently negligible value. Although emissivity compensation processes can be developed, the resulting system would probably be too complex and have limited applicability for field usage considering the wide variety of surface conditions to be encountered during routine inspection of waste storage drums. At this point, further evaluation of the thermography method was discontinued.

\subsection{SHEAROGRAPHY TECHNIQUES}

A subcontract was placed with LTI in Norristown, Pennsylvania, to conduct shearographic experiments using the 55-gal simulated corrosion specimen (test drum) described previously. These tests were performed to evaluate the possibility of using electronic shearographic techniques to locate and quantify the simulated flaws. These laboratory experiments were conducted using the following shearography instrumentation and test drum stressing equipment (Lape 1992):

- ES-9150 electronic shearography system using a krypton laser and phase imaging electronics

- VC-60 vacuum stressing test chamber

- ACAD-200 acoustic stressing system.

- Infrared heat lamp for thermal stressing

- MECAD 200 vibration stressing system

- VP-500 high-resolution video printer. 
Figure 2. Test Specimen Made Using the Lid From a New, Painted 55-gal Drum.

\section{Flaw Dimensions}

Drum-Lid Test Specimen

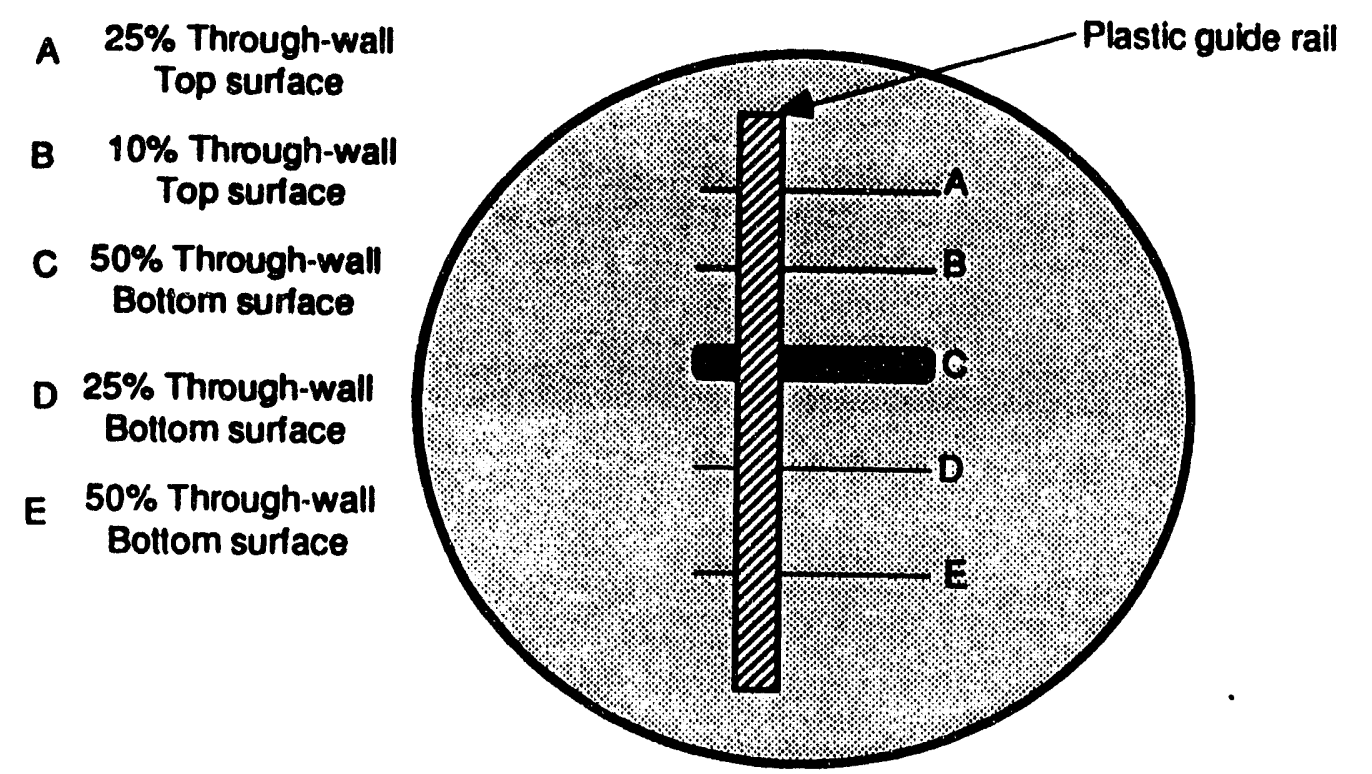

All notches are $0.038 \mathrm{in}$. wide and $1 \mathrm{in}$. long with the exception of $\mathrm{C}(0.500 \times 1 \mathrm{in}$.) 
Figure 3. Tast Specimen Made Using a Flat Plate of Mild Steel to Quantify the Magnetic Flux Leakage Response Signals.

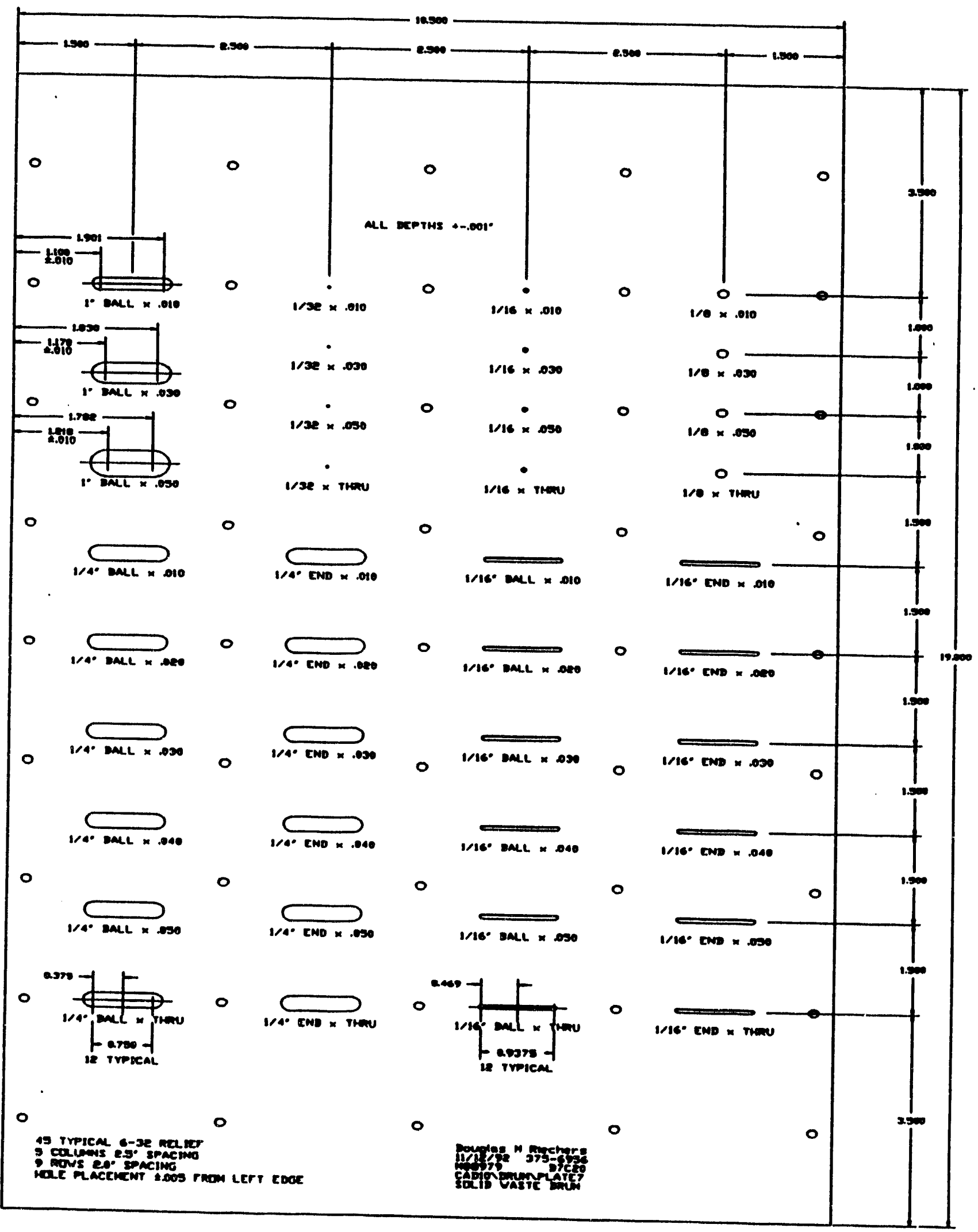


During these experiments, the test drum was placed in position and an initial "reference image" was captured using the ES-9150 system. The test drum was then stressed using each of the four stressing methods independently, and another shearographic image was captured while the test drum was under each different stress. The ES-9150 equipment was then used to compare the stressed and unstressed images, and a high-resolution print was made of the resultant image using the video output of the ES-9150 system.

The ACAD-200 acoustic vibration stressing system was air coupled to the test drum and operated over a frequency range of $650 \mathrm{~Hz}$ to $20 \mathrm{kHz}$. The MECAD200 mechanical vibration stressing system uses one or more (probably two for 55-gal drums) piezoelectric transducers that are mechanically coupled to the drum and are excited over a frequency range of 1-50 $\mathrm{kHz}$.

The stressing processes were implemented as follows:

- Pressure reduction loading--A pressure reduction of about 40 in. $\mathrm{H}_{2} \mathrm{O}$ or less was applied to the test drum within the $\mathrm{VC}-60$ vacuum test chamber.

- Air coupled acoustic drive--The test drum was excited using a highfrequency acoustic driver.

- Thermal loading--The surface temperature of the test drum was raised slightly using an infrared lamp and then allowed to cool to ambient temperature.

- Mechanical vibration loading--The test drum was mechanically vibrated over a range of frequencies using the MECAD-200 system.

The shearography results showed that the larger $(2 \mathrm{in}$. by 2 in. and 1 in. by 1 in.) flaws could be detected when they were $50 \%$ or $75 \%$ deep, and the $1 / 2$ in. by $1 / 2$ in. flaws could only be detected when they were $75 \%$ deep. In general, the larger and deeper flaws were detected and the smaller and shallower flaws were not detected. None of the part-through drilled holes (pointed-bottomed or flat-bottomed), nor the $1 / 4$ in. wide by $3 \mathrm{in.}$ long notches, were detected by the shearography method.

Table 2 is a listing of the flaws that were detected and the stressing mechanism(s) used for successful detection.

As shown in Table 2, the shearography method appears effective for 1 arge, deep flaws, marginally effective for small or shallow flaws, and ineffective for very small and/or shallow flaws (i.e., $1 / 2$ in. by $1 / 2$ in. by $25 \% \mathrm{~T}$, drilled holes, and narrow notches).

LTI concluded that implementation of shearography as a production inspection tool would be most effective using the MECAD-200 system for vibration stressing. During a telecon on November 4, 1992, it was learned that the LTI representatives expect that field implementation of this equipment will probably involve using a relatively narrow, optimized range of 
Table 2. Shearography Flaw Detection.

\begin{tabular}{|l|l|l|}
\hline $\begin{array}{c}\text { Flaw size } \\
\text { (inches) }\end{array}$ & $\begin{array}{c}\text { Wall thickness } \\
\text { (inches) } \\
\text { wall 105s) }\end{array}$ & \multicolumn{1}{|c|}{ Stressing method } \\
\hline 2 by 2 ID & $0.013(75 \%)$ & Acoustical, thermal, vacuum, vibration \\
\hline 2 by 2 ID & $0.026(50 \%)$ & Acoustical, thermal, vibration \\
\hline 2 by 2 ID & $0.039(25 \%)$ & Acoustical \\
\hline 1 by 1 ID & $0.013(75 \%)$ & Acoustical, thermal, vacuum, vibration \\
\hline 1 by 1 ID & $0.026(50 \%)$ & Acoustical, thermal, vibration \\
\hline .5 by .5 ID & $0.013(75 \%)$ & Thermal, vibration \\
\hline .5 by .5 ID & $0.026(50 \%)$ & Thermal, vibration \\
\hline 2 by 2 OD & $0.013(75 \%)$ & Acoustical, thermal, vacuum, vibration \\
\hline 2 by 2 OD & $0.026(50 \%)$ & Acoustical, thermal, vibration \\
\hline 2 by 2 OD & $0.039(25 \%)$ & Acoustical \\
\hline .75 dia. OD & $0.026(50 \%)$ & Acoustical, vibration \\
\hline .5 by .5 OD & $0.013(75 \%)$ & Acoustical, thermal \\
\hline
\end{tabular}

frequencies, rather than the full 1-50 kHz range that is possible. LTI thinks that the next step in this investigation, if it is continued, should be to perform further tests using drums with actual corrosion and some simulated contents, followed by field testing of their equipment on actual solid waste storage drums at the Hanford Site.

The LTI representatives suggested that the drums be inspected with a 60 degree field of view; requiring six images around the circumference at three heights (i.e., 18 images). This inspection should require about $3 \mathrm{~min}$ per drum, and flaw recognition and identification would be accomplished manually by an operator. A copy of the LTI report (Lape 1992), which includes 17 photographs showing the actual shearographic results, is provided in Appendix C.

\subsection{EDDY CURRENT TECHNIQUES}

One of the drum-1id test specimens was scanned using a flat "pancakecoil" type ET probe. Five different excitation signals ranging from $10 \mathrm{kHz}$ to $200 \mathrm{kHz}$ were applied to the test coil during these tests. As the probe passed over areas of known wall thinning, the resulting ET response was observed on the eddy scope display screen. During these tests, the ET probe was scanned 
over both sides of the test specimen; whereas, all of the artificial flaws were on only one side of the specimen. In addition to this test specimen, an old 55-gal drum with extensive corrosion on the inner surface was scanned to determine if the ET method could detect actual corrosion and provide a usable measure of wall thinning.

The ET experiments described above were repeated after applying a uniform magnetic field to the test specimens. A magnetic field that is strong enough to saturate the test specimen (i.e., move to a maximum along the $B$ versus $H$ hysteresis curve), prevents magnetic permeability changes in the steel from interfering with signals resulting from wall thinning or corrosion.

As the drum-lid was scanned without an applied magnetic field, surfaceconnected flaws produced large ET response signals with signal-to-noise ratios of at least $3: 1$. But when the flaws were located more than 0.008 in. beneath the surface, the ET response signals diminished below the noise level and could not be detected. If a strong magnetic field was applied to the test specimen and the noise level was reduced, the flaw detection rate improved. The magnetic field reduced the noise caused by magnetic permeability variations in the steel, allowing flaws located up to 0.015 in. below the surface to be detected. However, some noise due to permeability effects was still present.

Flaws located more than 0.015 in. below the surface could not be detected using the five coil excitation frequencies ranging from $10 \mathrm{kHz}$ to $200 \mathrm{kHz}$. The lover end of this frequency range gave the best results due to greater ET penetration. Theoretically, the applied ET frequencies must be below about $1 \mathrm{kHz}$ to completely penetrate the drum wall. However, when the frequency is reduced below $1 \mathrm{kHz}$, a saturating magnetic field is still needed for noise reduction because the drum material is ferromagnetic. The magnetic fieids used in this study were not strong enough to completely saturate the drum wall. Lower frequencies and stronger magnetic fields should facilitate the detection of discontinuities located more than 0.015 in. beneath the surface. Another possibility that was considered is the pulsed ET technique, where frequencies over a very wide range (typically between $10 \mathrm{~Hz}$ and $10 \mathrm{MHz}$ ) are applied in a single pulse. A literature search was conducted to investigate the potential of the pulsed ET technique.

A literature search was conducted to determine if a pulsed ET technique could provide any advantage over a conventional, single frequency ET method for this application. Forty-eight references were listed under detecting corrosion with pulsed ETs, but 47 of these described applications for examining stainless steel materials. The references most closely related to this study are listed in the reference section of this document. The one pulsed ET paper (Crostack, et al.) that discussed a carbon steel application was concerned with examining thin carbon steel coatings sprayed on nonferrous aircraft parts. It is assumed that the reason very few reports were found in the literature regarding the use of pulsed ETs to examine carbon steel is due to the problem of penetrating carbon steel with electromagnetic waves and separating magnetic permeability effects from electrical conductivity. 
Pulsed ETs are governed by the same physical principles as single frequency ETs. Pulsed ETs can be thought of as the superposition of many single frequency ET fields. Therefore, a pulsed ET technique is not expected to offer any advantages over a single frequency technique for corrosion detection in ferromagnetic steels because they are both limited by the intrinsic depth of penetration. Pulsed ETs are normally used for applications that require the simultaneous use of a broad range of frequencies.

\subsection{MAGNETIC FLUX LEAKAgE METHOD}

An experimental, breadboard MFL system was designed, fabricated, and tested. This system consists of a Hall effect sensor that detects small perturbations in magnetic fields along one axis and the associated electronics for converting these magnetic field measurements into a voltage display on an oscilloscope. The Hall sensor is rigidly coupled to a neodymium-27 magnet that produces a magnetic field capable of penetrating the steel wall of a 55-gal drum.

The magnet and $\mathrm{Hall}$ sensor were mounted on a four-wheeled carriage for rolling the probe assembly across a test specimen. Two MFL probe assemblies were fabricated, one for the cylindrical side wall of the drum and another for the flat surfaces (end covers). The output voltage from the Hall sensor was recorded on a storage oscilloscope for near real-time presentation of flaw indications. The size and shape of the distortion patterns in the magnetic field surrounding discontinuities are directly related to the geometry of the flaw that distorted the magnetic field. The Hall sensor and its associated electronics detect this distortion pattern and generate a voltage that is proportional to the amount of distortion that occurs in the induced magnetic field when a discontinuity is encountered.

Initial MFL testing was performed using the notched, drum lid test specimen described above and shown in Figure 2. As the MFL probe assembly was scanned across the drum lid, several observations were made. The most significant were:

- Repeated scans yielded reproducible Hall output voltages (within oscilloscope resolution) for each of the five notches

- Flaw response signals from the smallest notch were readily detectable

- The notches were detected equally well with the probe on either side of the test specimen (i.e., the side either adjacent to or opposite the notches)

- Response signal amplitude was relatively independent of probe speed as the probe was scanned across the drum surface

- Output voltage amplitude generally increased with increasing flaw depth

- Output voltage signal width increased with increasing flaw width. 
Although these results were not very quantitative, they demonstrated the potential of this approach for detecting material loss from the inner or outer surfaces of a 55-gal drum. Flaw depths, measured during test specimen fabrication, were used for the estimated flaw depth values shown in Figure 2. Another consideration was variability in MFL probe speed. As the probe moved slower, the voltage trace spanned a wider distance on the oscilloscope screen. Probe speed is not critical for this test, as long as it remains relatively constant. When the probe speed was changed during a scan, the time base for individual flaws was different than for flaws scanned at a different speed. The distance or time between extremes in Hall voltage, as the probe passed a particular flaw, provided a measure of flaw width along the path of the Hall
sensor.

The magnetic field generated by the MFL probe was strong enough to cause the hand-held probe carriage to slow down and speed up, resulting in a "jerky" motion when it interacted with a discontinuity in the drum wall. The jerky probe motion produced output voltage fluctuations exceeding those produced by a discontinuity. Effects caused by nonuniform probe motion were eliminated by scanning the flat, steel test plate that contained precisely machined discontinuities (Figure 3 ). The scanning system repeatedly scanned each flaw at the same constant rate.

Further tests were conducted using this method on the outer surface of the 55-gal test drum and those results are shown in Figure 4. A trend, toward increased Hall voltage with decreased wall thickness (i.e., deeper flaws), was observed. This test demonstrated an important point regarding the capabilities of this method--the relationship between output voltage and uncorroded wall thickness. However, Figure 4 shows at least two flaws, No. 103 and No. 109, that did not follow this trend. As noted earlier, it was difficult to accurately machine flaws into the curved drum surface and both flaw Nos. 103 and 109 were found to have irregular depths and shapes. Depth and shape measurements showed that these irregularities ranged from 25 to $30 \%$. A more quantitative experiment was needed to determine the accuracy that could be achieved using this method for measuring drum wall thickness.

Another test specimen was fabricated to provide more precise notches and holes to quantify the capability of the MFL method for measuring the size of flaws in a $0.0625-i n$. thick steel sheet, as demonstrated in figure 3 . The maximum voltage output from the Hall effect probe as it was scanned past each flaw (in one of four different flaw series) was plotted versus flaw depth as shown in Figure 5. The flaw depth measurements were accurate to \pm 0.0003 in. and the output voltage measurements were accurate to $\pm 35 \mathrm{mV}$ within a $20-V$ range. Flaws with the same shape that were larger than about 1/16-in. diameter exhibited an almost linear relationship between flaw depth and Hall voltage. However, for flaws with different shapes, the Hall voltage seems to be related to both the shape and volume of the flaw. For example, the ball mill produced a round bottomed groove with less removed material than the end mill, and the end mill groove produced greater response. For flaws less than 1/16-in. diameter, a somewhat exponential relationship was observed. Scanning 
Figure 4. Plots Showing Magnetic Flux Leakage Response (Hall Voltage) and Remaining Wall Thickness (Flaw Depth) for Inner Surface Flaws in the Test Drum.
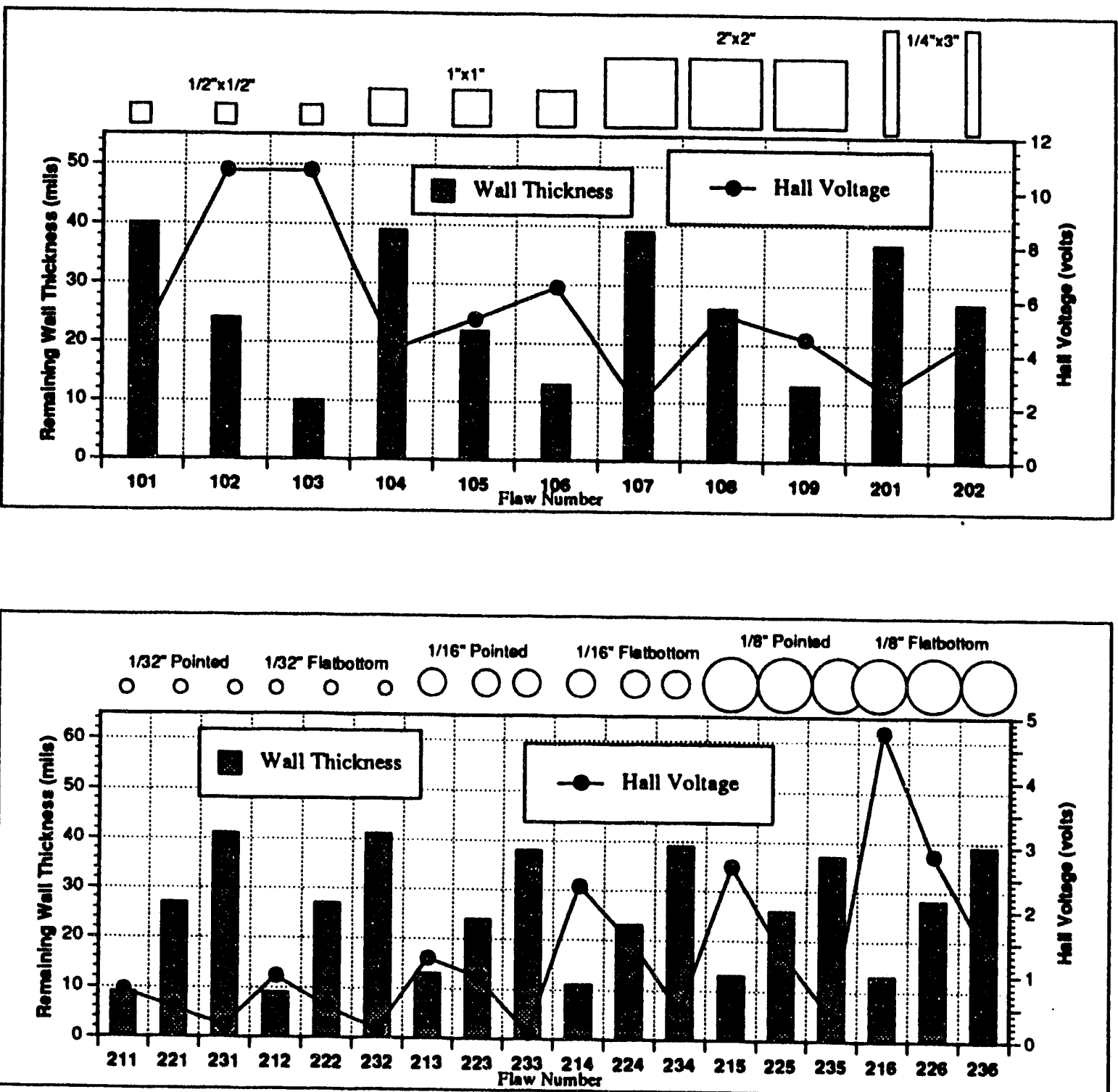
across a through-wall notch resulted in a 20-volt peak-to-peak output signal and the smallest drill hole (1/32-in. diameter by $0.010-i n$. deep) gave a $0.250 \mathrm{~V}$ peak-to-peak response at the same gain setting. The sensitivity to small discontinuities could be increased by increasing the gain. A typical output voltage recording is displayed in Figure 6.

MFL produces a vector field, which means that at each point it has both an amplitude (i.e., a flux density) and a direction. The Hall effect sensor used in this study measured only one component (the component perpendicular to the metal surface) of the flux leakage field. In this manner, the MFL technique detects metal-loss regions that cause magnetic flux to leak away from the surface. The measured fiux leakage field depends on the depth, length, width, and shape of the metal-loss region. This accounts for the difference in $\mathrm{Hall}$ voltages recorded from the square-bottomed mill cut and the ball-shaped mill cut.

Analysis of an arbitrary flux leakage field, to characterize the geometry of a metal-loss region, can be a complex task. However, many corrosion inspection applications do not require reconstruction of the exact metal-loss geometry; only the approximate depth and sometimes the width. Once the depth of corrosion exceeds some limit, the part in question fails the inspection (or must be analyzed further by another method) and no further MFL analysis is necessary. The analysis required to determine absolute changes in wall thickness was not performed during this Phase I study. The MFL data collected from the 55-gal test drum and the flat steel plate were only examined for peak Hall output voltage. The Hall output voltage signals recorded during Phase I will be analyzed during Phase II for predicting absolute metal-loss and the accuracy associated with this measurement.

Several modifications are being made to optimize this method and determine what level of MFL system performance is appropriate for this application. Rearrangement of the magnets may alter the magnetic field shape enough to improve detection of certain types of corrosion and discriminate against unwanted signals. Also, only one type of Hall sensor has been tested for this application; at least two other types should be evaluated before starting the design of a sensor array to scan larger areas.

Work completed to date on the MFL method shows that both large and small flaws can be detected and sized at reasonable scanning rates for inspecting actual drums in the field. Further laboratory testing will focus on drums that exhibit the different forms of corrosion that occur on 55-gal drums. 
Figure 5. Maximum Voltage Output From the Magnetic Flux Leakage Probe Versus Depth of Flaws Located on the Back Surface of the Steel Test Plate Shown in Figure 3.

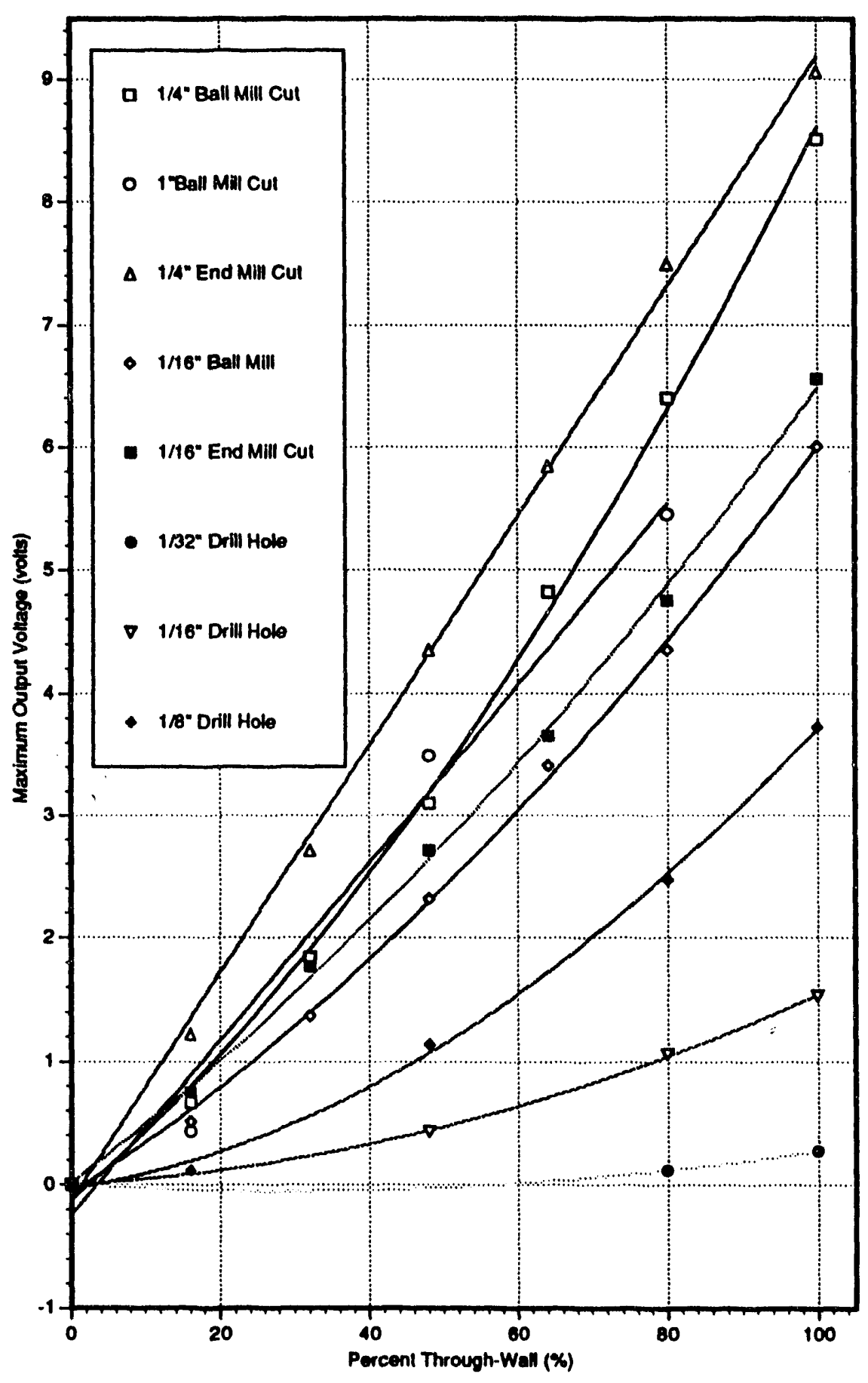


Figure 6. Output Voltage Recorded at 0.0005 in. Intervals as the Magnetic Flux Leakage Probe Scanned Each of the Four Lines of Flaws on the Steel Test Plate Shown in Figure 3.
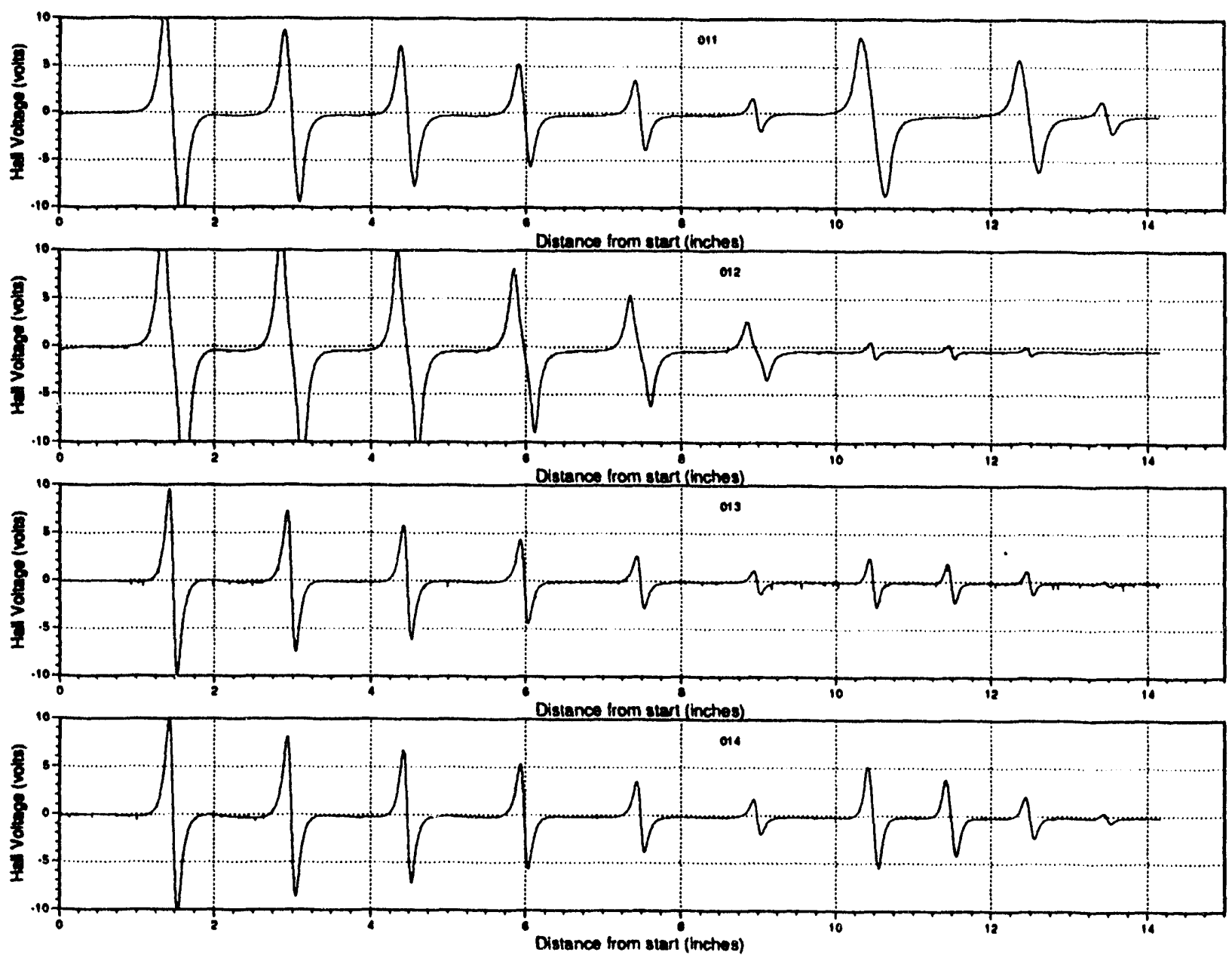
WHC-EP-0660

\subsection{CONCLUSIONS AND RECOMMENDATIONS}

On the basis of the literature survey, it appears that interest in this application is 1 imited to the nuclear industry. Reports obtained during the survey described feasibility studies where RTR and CT were evaluated for this application. It appears that an RTR/CT system could be developed to provide an effective inspection; however, the cost and complexity of such a system, combined with a relatively slow inspection rate, limits the attractiveness of this method.

A visit to the drum storage sites at the Hanford 200 Areas was very enlightening because it provided firsthand insight into the nature and constraints associated with NDT. The INEL/RWMC at Idaho Falls was visited to observe the SWEPP facilities. This trip provided an opportunity to broaden our perspectives of the DOE waste management process, and to observe demonstrations of the UT and RTR systems used at the SWEPP. The UT equipment at the SWEPP can detect oxide (corrosion) buildup of 0.01 in. or more and measure wall thinning changes as small as 0.001 in. The SWEPP system was developed in the early 1980s with a total estimated cost of $\$ 200,000$ (development plus capital costs). Current technology, while considerably more costly, could be employed to provide a system with much greater capability and sophistication; particularly in the areas of data acquisition, presentation, and recording. However, the SWEPP system only provides measurements for $1 / 16$ in. Wide scan paths at eight separate barrel locations, and a samplingtype scanning scheme will not satisfy the WHC design requirement to inspect 100\% of the barrel surface.

Two separate brainstorming sessions were held in an effort to develop techniques and concepts for detecting general and localized corrosion. This problem was initially divided into seven subelements, and these seven were reduced to the following four key subelements (1) wail thickness, (2) pinhole corrosion, (3) bottom crimped joint, and (4) screening techniques. The most promising NDT methods that were identified included MFL, shearography, and ET techniques.

Limited stress analysis calculations to estimate the maximum external pressure that could be applied to a drum showed that the buckling pressure for the shell area was about $56, \mathrm{lb} / \mathrm{in}^{2}$; whereas, the end-covers could only tolerate about 1 to $2 \mathrm{lb} / \mathrm{in}^{2}$. Thus, lid collapse limits the maximum applied pressure to 1 to $2 \mathrm{lb} / \mathrm{in}^{2}$. Separate calculations indicated that a $1 \mathrm{lb} / \mathrm{in}^{2}$ leak through a 0.01 in. diameter hole might be detectable using the $A E$ method. Unfortunately, the practical difficulties associated with handiing and pressurizing drums, plus the knowledge that this method offers little promise for detecting nonleaking corrosion-thinned areas, 1 imits the attractiveness of this approach.

Laboratory tests and literature searches were conducted to evaluate the feasibility of the thermography, shearography, ET, and MFL methods. On the basis of these tests, it was concluded that neither the thermography nor the ET methods offered sufficient promise for satisfying the applicahle inspection 
requirements. For both of these methods, overly expensive and complex peripheral systems would be required to compensate for the adverse effects of variations in surface emissivity (for thermography) and magnetic permeability (for ETs). With this conclusion, experimental work was discontinued on both of these methods.

Under a subcontract with LTI, experiments were performed to evaluate shearography. A test drum, fabricated and provided by PNL, was stressed using vacuum, acoustics, heat, and vibration. The shearography results showed that the largest ( 2 in. by 2 in. and 1 in. by 1 in.) flaws could be detected when they were $50 \%$ or $75 \%$ deep, and the $1 / 2$ in. by $1 / 2$ in. flaws could only be detected when they were $75 \%$ deep. None of the part-through drilled holes, nor the $1 / 4$ in. wide by 3 in. long notches, were detected using shearography. The LTI concluded that field implementation of shearography should employ vibration stressing. Further tests using drums with actual corrosion and perhaps simulated contents, followed by field testing of the LTI equipment at Hanford, were recommended as future work.

The MFL method offers the best potential for satisfying the inspection requirements that WHC has established for solid waste storage drums. All of the artificial flaws in the test drum were reliably detected using a nonoptimized, breadboard MFL system. It was also determined that the rate of inspection would be limited by the scanning system rather than the MFL instrumentation. On the basis of the laboratory tests conducted to date, it appears that the MFL method is potentially capable of providing measurements of the depth and overall shape and size of corrosion-type flaws. Both pitting corrosion and gross corrosion appear to be readily detectable and generally quantifiable using the MFL method. The capability of this method for detecting true pinhole corrosion has not been evaluated; however, pointedbottom drill holes that were $1 / 32$ in. diameter and $25 \%$ through-wall were readily detectable using a nonoptimized breadboard system.

Based on this Phase I feasibility study, it is concluded that inspection of 55-gal, solid waste storage drums represents a formidable technical problem. It is also concluded that the MFL method appears to offer a viable solution to this inspection problem. The shearography method, while not capable of detecting small or medium sized flaws, is potentiaily capable of serving as a screening test that could be used to segregate drums with gross corrosion from drums that are sound.

On the basis of the work described in this, we recommended that additional development and evaluation of the MFL method be authorized. Appendix A describes the scope of work that should be performed during FY 93 and FY 94.

It is further recommended that, if additional funds can be made available, a subcontract should be placed with LTI for further tests using drums with actual corrosion and perhaps simulated contents. Such drums could probably be identified and procured by LTI to avoid the cost of shipments from Hanford. If these tests are successful, field testing of the LTI equipment on actual solid waste storage drums at the Hanford Site should be considered if a gross screening method is needed. 


\subsection{REFERENCES}

Barna, B. A., B. N. Brown, and B. C. Anderson, 1983, Automated NDT Techniques in Radioactive Waste Management, EG\&G Idaho, Inc., Idaho Falls, Idaho.

Bernardi, R. T., 1990, "The Feasibility of Using Digital Radiography and Computed Tomography to Characterize Sol idifled Low Level Nuclear Waste," Workshop on Radioactive, Hazardous, and/or Mixed Waste Sludge Management Knoxvilie, Tennesee.

Bio-Imaging Research, Inc., ACTIS + Upgrade for RTR, Lincolnshire, Illinois,

Bishoff, J. R., 1982, A Technical Plan for Development of Nondestructive Examination Technology, EGG-WM-5815, EG\&G Idaho, Inc., Idaho Falls, Idaho.

Bruno, R. P., 1989, "Thermography in Nondestructive Industrial Testing," Photonics Spectra, Vol. 23, pp. 123-126.

Cook, J. F., D. A. Aldrich, B. C. Anderson, and V. S. Scown, 1984, "Development of an Automated Uitrasonic Inspection System for Verifying Waste Container Integrity," Mat. Eval. Vol 42, No. 13, Pp. 1626-1630.

Crostack, H. A., W. Jahnel, J. Kohn, B. Polaud, 1989, "Non-Destructive Quality Evaluation of Thermaliy Sprayed MCrAlY Protective Coatings With the CS-Pulsed Eddy Current Method," Thermal Spraying, Vol.1, Pp.4-9.

Hinckley, J. P., 1982, A Technical Plan for the Development of an Assay system for INEL-Stored TRU Waste, EGG-WM-5792 Rev. 1., EG\&G Idaho, Inc., Idaho Falls, Idaho.

Hung, Y. Y., 1989, "Shearography: A Novel and Practical Approach for Nondestructive Evaluation," JNDE Vol. 8, pp. 55-67

Kettschau, A., P. Reimers, and J. Goebbles, 1985, Jahrestagung Kerntechnik 85: Computertomographie von Radioactiven Abfallgebinden. Deutsches Atomforum e.V., Bonn, Germany (F.R.).

Kuo, P. K., T. Ahmed, L. D. Favro, H-J Jin, and R. L. Thomas, 1989, Synchronous Thermal Wave IR Video Imaging for Nondestructive Evaluation, JNDE 8, PP. 97-106.

Lape, D., 1992, Shearography NDE of a 55 Gallon Drum Test Specimen, Laser Technology Inc., Report, TR 92-72, Norristown Pennsylvania. 
Pickett, C. A., D. W. Koerner, W. E. Deeds, and C. V. Dodd, 1988, "Pul sed Eddy Current Method for Examining Thin-Walled Stainless Steel, "Review of Progress in Quantitative Nondestructive Evaluation, Vol. 7B, pp. 1695-1702

Wittig, G., H. M. Thomas, D. Maser, P. Hennig, G. Weigelt, 1986, The Application of Pulse Eddy-Current Process For the Non-destructive Testing of Austenitic Pipes Damaged by Corrosion, INIS-MF-11686, Bundesanstalt fuer Materialpruefung, Berlin, Germany, (F.R.). 
WHC-EP-0660

APPENDIX A

PROPOSED MORKSCOPE

A-1 
WHC-EP-0660

This page intentionally left blank. 
WHC-EP-0660

\title{
APPENDIX A
}

PROPOSED MORK SCOPE

\author{
Waste Container NDE, Task $\mathrm{J}$ \\ Solid Waste Technology Support Project
}

Development and evaluation of candidate methods to detect general and localized corrosion in 55-gal drums is recommended. As requested by Westinghouse Hanford Company (WHC), this fiscal year (FY) 1993 budget request of $\$ 100,000$ will be used to complete the Phase I work (including report issuance), complete most of the Phase II work, and initiate the Phase III work. The proposed schedule and deliverables is contingent upon prompt Pacific Northwest Laboratory (PNL) receipt of the FY 93 funding authorization.

COMPLETE FEASIBILITY STUDIES

Phase I - $\$ 25,000$

\section{Shearography Technique}

An initial shearography evaluation was completed in late FY 92 by Laser Technology, Inc. (LTI) under subcontract using the special test drum fabricated to simulate actual corrosion. PNL will evaluate the LTI experimental results which involved several stressing techniques; 1.e., acoustical, thermal, vibration, and vacuum. PNL will complete this evaluation based on the LTI results and document this assessment for inclusion in the Phase I feasibility report.

\section{Eddy Current Techniques}

The feasibility of the pulsed ET technique will be evaluated in early FY 93 by conducting a literature search using the facilities of the PNL Technical Library. This search will focus on applications involving the use of pulsed ET techniques to detect flaws or thinned areas in thin sections of mild carbon steels. The information obtained from the search, and the results of the single-frequency laboratory tests, will be documented for inclusion in the overall Phase I report.

\section{Phase I Feasibility Report}

A draft of the Phase I report covering all of the feasibility studies conducted under this project will be completed and provided to WHC for review in early FY 93. Upon receipt of WHC comments, this report will be finalized and issued as an informal letter report to document the Phase I feasibility results. 
For the magnetic flux leakage (MFL) method, the existing breadboard electronics package and probe assembly will be optimized for laboratory tests using the corrosion simulation and test specimen (i.e., test drum) fabricated during FY 92. Laboratory and mockup tests will be performed to provide simulated inspection experience for use in designing a prototype system for field tests and evaluations. Selected feature tests will be conducted using the laboratory system. Design and performance criteria for a prototype system will be estabilished and provided to WHC for review. The Phase II costs shown above are FY 93 only, al though the schedule and deliverables show that the Phase II work scope extends into FY 94.

PROTOTYPE SYSTEM

Phase III - $\$ 25.000$

Assuming Phase II is successful, a prototype, field-usable flux leakage system will be designed and assembled, and field testing of selected 55-gal drums in the 300 and 200 Areas will be initiated. Additional feature tests will be conducted to verify the practicability of key system attributes and functions such as the scanning system, detection of pitting and/or pinhole corrosion at production scanning rates, and data acquisition and recording subsystems. The Phase III costs shown above are FY 93 only, al though the schedule and deliverables shows that the Phase III work scope extends through FY 94.

OUALITY ASSURANCE IMPACT LEVEL: PNL Level III (WHC Leve1 IV)

A time-phased chart for FY 93 and FY 94 work is attached (Figure A-1). 
Table A-1. Schedule and Deliverables.

\begin{tabular}{|c|c|}
\hline Deliverable & Date \\
\hline Phase I & $\$ 25,000$ \\
\hline Complete evaluation of shearography results & $11 / 01 / 92$ \\
\hline Complete evaluation of pulsed ET techniques & $11 / 15 / 92$ \\
\hline Submit draft Phase I report to WHC for review & $12 / 01 / 92$ \\
\hline Finalize and issue Phase I report & $\begin{array}{l}1 \text { month after } \\
\text { receipt of WHC } \\
\text { comments }\end{array}$ \\
\hline Phase II & $\$ 50,000$ \\
\hline Initiate Phase II laboratory and mockup tests & $12 / 01 / 92$ \\
\hline Submit draft system design/performance criteria to WHC & $04 / 01 / 93$ \\
\hline Complete preliminary laboratory and mockup tests & $05 / 01 / 93$ \\
\hline Review conceptual system design (joint PNL and WHC)* & $09 / 01 / 93$ \\
\hline Initiate key function feature tests* & $05 / 15 / 93$ \\
\hline Phase III & $\$ 25,000$ \\
\hline Complete design of prototype system* & $10 / 01 / 93$ \\
\hline Complete key function feature tests* & $03 / 15 / 94$ \\
\hline Develop, procure, assemble, and debug system* & $04 / 15 / 94$ \\
\hline Submit draft acceptance test plan to WHC* & $05 / 01 / 94$ \\
\hline Complete formal acceptance test* & $06 / 01 / 94$ \\
\hline $\begin{array}{l}\text { Deliver prototype system (including operating and } \\
\text { maintenance manual) to WHC* }\end{array}$ & $09 / 01 / 94$ \\
\hline $\begin{array}{l}\text { Submit final informal document (draft) to WHC for } \\
\text { review* }\end{array}$ & $09 / 30 / 94$ \\
\hline
\end{tabular}

* Within the limit of available funding for the applicable fiscal year. 
Figure A-1. Milestone Chart of FY 93 and FY 94.

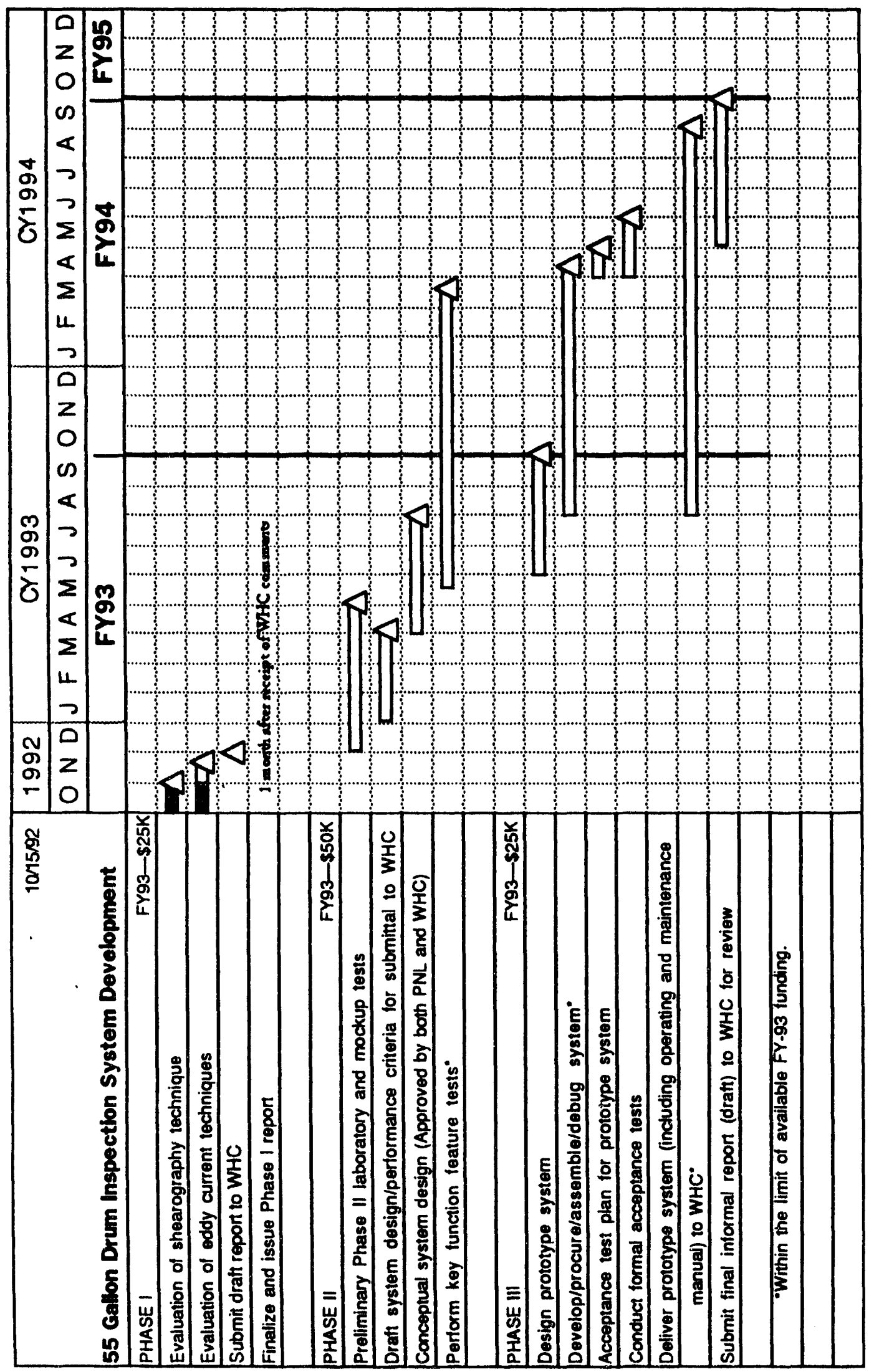


WHC-EP-0660

APPENDIX B

DISCUSSION OF MAGNETIC FLUX LEAKAGE SYSTEM CAPABILITIES COMPARED TO THE INITIAL INSPECTION REQUIREMENTS/CRITERIA PROVIDED BY MESTINGHOUSE HANFORD COMPANY 
WHC-EP-0660

This page intentionally left blank. 


\section{APPENDIX B}

\section{DISCUSSION OF MAGNETIC FLUX LEAKAGE SYSTEM CAPABILITIES CONPARED TO THE INITIAL INSPECTION REQUIREMENTS/CRITERIA PROVIDED BY WESTINGHOUSE HANFORD COMPANY}

1. Range of wall thicknesses

- Department of Transportation (DOT)-Type 17-H--0.050 (nominal), 0.043 (minimum)

- DOT-Type 17-C--0.060 (nominal), 0.053 (minimum).

Thicknesses compatible with MFL method

2. Coated surfaces

- Inner surfaces - no problem

- Outer surfaces - rough surfaces will require special probe considerations.

3. Thickness accuracy of \pm 0.005 in. required for smooth portion of shell and top cover

4. Minimum area of detectable corrosion $0.01 \mathrm{in}^{2}$

5. Total inspection time of 15 mins or less - to be determined (TBD) under Phase II

6. Inspect top and bottom rolled edges - TBD under Phase II

7. Automated and semi-automated data reduction and display - TBD, but intrinsically compatible with MFL

8. Noncontacting probe/sensor - possible, TBD under Phase II

9. Inspect bottom of upright drums - TBD under Phase II.

Because the MFL method is only sensitive to metal-loss, the two different 55-gal drum types $(17-H, 17-C)$ pose no problems for the MFL method. The MFL method was equally effective during this study on metal thicknesses ranging from $0.043 \mathrm{in}$. to $0.0625 \mathrm{in}$. The MFL method is expected to be insensitive to coatings on the inside surface including rust, and should only provide a response to regions of metal-10ss. However, if the outside surface becomes rough or "bumpy" due to rust, the design of a surface riding probe would become more difficult, but not impossible. In the event of rough spots on the outside surface, some type of lift-off compensating scheme would be required to counteract the possibility of probe-to-drum motion. 
The MFL method has been used in other applications for monitoring steel wall thicknesses to an accuracy of $\pm 10 \%$, for metal-loss greater than $25 \%$ of total wall thickness. When the metal-loss is less than $25 \%$ of the expected wall thickness the accuracy may be worse than $\pm 10 \%( \pm 0.005$ in. for most drums). The smallest drill hole examined and detected in this study was $0.0312 \mathrm{in}$. diameter and $0.006 \mathrm{in}$. deep; however, the breadboard system had not been optimized for the maximum sensitivity. The time required to inspect a 55-gal drum will be determined during Phase II after the laboratory system has been assembled and optimized. It is recognized that this inspection must be performed in real time (or nearly real time), and that the equipment must function in the 200 Areas at Hanford. These are design criteria and design goals that will be addressed during Phase II.

Inspecting the drum's top and bottom rolled edges with an MFL method cannot be ruled out at this time, but will require bench testing to determine feasibility. Automated or semi-automated data reduction and readout capabilities are intrinsically compatible with the MFL method, and the Phase II work will include defining the data acquisition mode and the amount of data required to achieve system specifications. A noncontacting probe and sensor system was not investigated in this study but will be considered during Phase II. For the MFL method to inspect the drum bottom, the drum must be raised up enough for an MFL probe to fit between the drum bottom and the floor or pallet. If the drum must maintain contact with the floor or pallet, there is little chance of inspecting the drum bottom with the MFL method. 
WHC-EP-0660

\section{APPENDIX C}

LASER TECHNOLOGY INCORPORATED FINAL REPORT SHEAROGRAPHY NONDESTRUCTIVE EVALUATION OF A 55 GALLON DRUM TEST SPECIMEN 
WHC-EP-0660

This page intentionally left blank. 
WHC-EP-0660

TR 92-72

\section{Pinal Report}

shearography NDE of a

55 Gallon Drum Test Specimen

Battelle Pacific Northwest Laboratories

Contract \#123554-A-M2 
TR $92-72$

Shearography NDE of a

55 Gallon Drum Test Specimen

D. Lape

\subsection{Introduction}

A steel 55 gallon drum test specimen was submitted by Battelle Pacific Northwest Laboratories, Richla , WA to Laser Technology, Inc., Norristown, PA for shearography $n$...destructive evaluation (NDE). Tests were performed on this sample in order to demonstrate the ability of Electronic Shearography to locate regions of corrosion, damage, and defects. The results of these tests have shown that Electronic Shearography can detect defects as small as .5" $x$. 5" $50 \%$ through .052" steel and $2 " x 2 " 25 \%$ through the wall thickness of .052" steel.

Liaison with Laser Technology, Inc. for this test was Mr. Jack Spanner of Battelle Pacific Northwest Laboratories. This work was performed under contract number $123554-\mathrm{A}-\mathrm{M} 2$.

\subsection{Test Sample}

The steel 55 gallon drum test specimen submitted for inspection was created with a number of defects ranging in size from 2 " $x$ " to 1/32" in diameter. The wall thickness of the defective areas varied 25\%,50\%, and $75 \%$ of the nominal wall thickness (.052"). Figure \#1 is a map of the flaws produced by Battelle Pacific Northwest Laboratories.

\subsection{Test Equipment}

The equipment used to perform the shearographic evaluation of the 55 galion drum consisted of the following:

1. ES-9150 Electronic Shearography system utilizing a Krypton laser and Phase Imaging electronics.

2. Vacuum stressing using a vc-60 vacuum test chamber.

3. Acoustic stressing using an ACAD-200 system.

4. Thermal stressing using an infrared heat lamp.

5. Vibration stressing using the MECAD-200 system. 


\section{LTI}

6. Images captured on disk and printed using a VP-500 high resolution video printer.

\subsection{Test Procedure}

The following test procedure was used in the shearographic NDT evaluation of the Battelle 55 gallon drum test specimen.

1. The test specimen was positioned within the vc-60 vacuum test chamber.

2. An initial "reference" image of the test sample illuminated by laser light was captured by pressing the "Refresh" button on the ES-9150 Control Console.

3. The test sample was then stressed using each of the following test methods independently.

- Pressure Reduction Loading: A pressure reduction of approximately 40 " $\mathrm{H}_{2} \mathrm{O}$ or less was applied to the test sample within the VC-60 vacuum test chamber.

- ACAD (Air Coupled Acoustic Drive): The test sample was excited by the use of a high frequency acoustic driver.

- Thermal Loading: The surface temperature of the test sample was raised slightly with the aid of an infrared lamp and then allowed to cool down to ambient temperature.

- Mechanical Vibration Loading: The test sample was mecahanically vibrated over a range of frequencies using our MECAD-200 system.

4. The development of shearographic fringe information was observed on the surface of the test sample during stressing, and the resultant shearographic image was frozen on the ES-9150 Control Console Monitor.

5. A high resolution print was produced using the video output of the ES-9150 Shearography Control Console. 


\subsection{Test Results}

\section{Inner Diameter Defects}

Photo 1 shows the shearographic results obtained on the 2 " $x$ " defect with a wall thickness of .013" (75\% missing) when acoustically excited. The bright area in the center of the photo indicates the location of the defect and can be seen quite clearly.

Photo 2 shows the shearographic results obtained on the 2 " $x 2$ " defect with a wall thickness of .026" (50\% missing) when acoustically excited. Again, the very bright area in the center of the photo represents the location of the defect. The indication on the left side of the photo is also the same defect seen in photo 1 .

Photo 3 shows a closer view of the shearographic results obtained on the $2 " x 2 "$ defect with a wall thickness of .013" (75\% missing) when acoustically excited. A distinct bright indication can be seen were the defect exists.

Photo 4 shows, using the same field of view as photo 3 , the shearographic results obtained on the $2 " x 2^{\prime \prime}$ defect with a wall thickness of .026" (50\% missing) when acoustically excited. This indication is not as bright as the defect is photo 3 , but is still easily visible.

Photo 5 shows, using the same field of view as photo $3 \& 4$, the shearographic results obtained on the $2 " x 2$ " defect with a wall thickness of .039" (25\% missing) when acoustically excited. The white indication below the crosshairs shows the location of the defect.

Photo 6 shows the shearographic results obtained on the 2 " $x 2$ " defects, with wall thicknesses of .013" and .026" (75\% \& 50\% missing), when mechanically vibrated. The two bright indications can be seen quite clearly showing the defects locations.

Photo 7 shows the shearographic results obtained on the 1 " $x 1^{\prime \prime}$ defects, which have wall thicknesses of .013" and .026" (75\% and $50 \%$ missing), when acoustically excited. The bright indication on the left is the .013" and the indication on the right is the $.026 "$ defect.

Photo 8 shows the shearographic results obtained on the 1 " $x 1^{\prime \prime}$ defects, which have wall thicknesses of .013" and .026" (75\% and $50 \%$ missing), when mechanically vibrated. The bright indication on the left is the .013" defect and the indication on the right is the .026" defect. 
Photo 9 shows the shearographic results obtained on the .5" $x .5$ " defects, which have wall thicknesses of .013" and .026" (75\% and 50 missing), when mechanically vibrated. The defects appear as small circular bright areas on the photo. The indication on the right is the $.026^{\prime \prime}$ defect and the indication on the left is the .013 " defect.

Photo 10 shows a "live" sheared image of the .5" $x .5$ " defect with a wall thickness of .013" (75\% missing).

Photo 11 shows the shearographic results obtained on the . 5 " $x$ .5" defect with wall thickness of .013" (75\% missing) when thermally stressed. The defect is located in the area where Ehere is a concentration of fringes and where the fringes change suddenly from their smooth circular type behavior. This area is circled in the photo and appears as "pinched" fringes.

Photo 12 shows the shearographic results obtained on the . $5^{\prime \prime} \mathrm{x}$ .5" defect with wall thickness of .026" (50\% missing) when thermally stressed. The area of "pinched" fringes again give away the location of the defective area.

Photo 13 shows the shearographic results obtained on the 2 " $x 2$ " defect with wall thickness of .013" (75\% missing) when a eressure reduction load is used. The small bright indication is the defect while the two larger indications show the location of the weld seam of the drum.

Photo 14 shows the shearographic results obtained on the 1 " $x 1$ " defect with wall thickness of .013" (75\% missing) when a pressure reduction load is used. The concentration of the double lobed circular fringes shows the location of the defect and is circled in the photo.

\section{Outer Diameter Defects}

Photo 15 shows a "live" sheared image of the 2 " $\times 2 " .013 "$ (75\% missing) and the .039" (25\% missing) wall thickness defects on the outer diameter.

Photo 16 shows the shearographic results obtained on the 2 " $x 2$ " defects with wall thicknesses of .013" (75\% missing) and the $.039 "$ (25\% missing) when acoustically excited. The very bright indication on the left is the .013" wall thickness while the more faint indication on the right is the .039" wall thickness defect. 
Photo 17 shows a "live" sheared image of the .5" x .5" .013"(75\% missing) and the .039" (25\% missing) wall thickness defects along with the .75" diameter defect with a .026" (50\% missing) wall thickness.

Photo 18 shows the shearographic results obtained on the $.5 " x .5 " .013^{\prime \prime}$ and .039" wall thickness and the .75" diameter $.026 "$ wall thickness defects when acoustically excited. The bright indication on the right is the $.75^{\prime \prime}$ diameter .026 " wall thickness defect while the indication on the left is the $.5 " x .5 " .013 "$ wall thickness defect.

\subsection{Conclusions}

The shearography NDE performed on the Battelle 55 gallon drum test specimen has shown that Electronic Shearography is capable of detecting corrosion type defects. The following is a table of defects detected and the stressing mechanism used to detect them.

Defect size

$\begin{array}{ll}2 " x 2 " \text { ID } & .013 " \\ 2 " \times 2 " \text { ID } & .026 " \\ 2 " \times 2 " \text { ID } & .039 " \\ 1 " \times 1 " \text { ID } & .013 " \\ 1 " \times 1 " \text { ID } & .026 " \\ .5 " \times .5 " \text { ID } & .013 " \\ .5 " \times .5 " \text { ID } & .026 " \\ 2 " \times 2 " \text { OD } & .013 " \\ 2 " \times 2 " \text { OD } & .026 " \\ 2 " \times 2 " \text { OD } & .039 " \\ .75 " D i a . O D & .026 " \\ .5 " x .5 " \text { OD } & .013 "\end{array}$

\section{Stressing Method}

Acoustical, Thermal, Vacuum, Vibration

Acoustical, Thermal, Vibration Acoustical

Acoustical, Thermal, Vacuum, Vibration

Acoustical, Thermal, Vibration Thermal, Vibration

Thermal, Vibration

Acoustical, Thermal, Vacuum, Vibration

Acoustical, Thermal, Vibration Acoustical

Acoustical, Vibration

Acoustical, Thermal

To implement shearography as a production tool for the inspection of 55 gallon drums with waste products, vibration stressing of the drum with mechanically coupled excjtors offers the fastest inspection capability and the best defect resolution. In this case, the drums could be inspected with a $60^{\circ}$ field of view, requiring 6 images around the circumference at three heights. 
Eighteen images requiring 180 seconds (including automatic rotation of the drum on a motor driven turn table) would be required to do the inspection. Defect recognition could be accomplished manually by the operator or loaded by a small robotic lift device allowing operation by a single person.

Request for additional information or questions concerning this report should be directed to either Mr. John Newman or Mr. Dale Lape of Laser Technology, Inc. at 215-631-5043. 
WHC-EP-0660

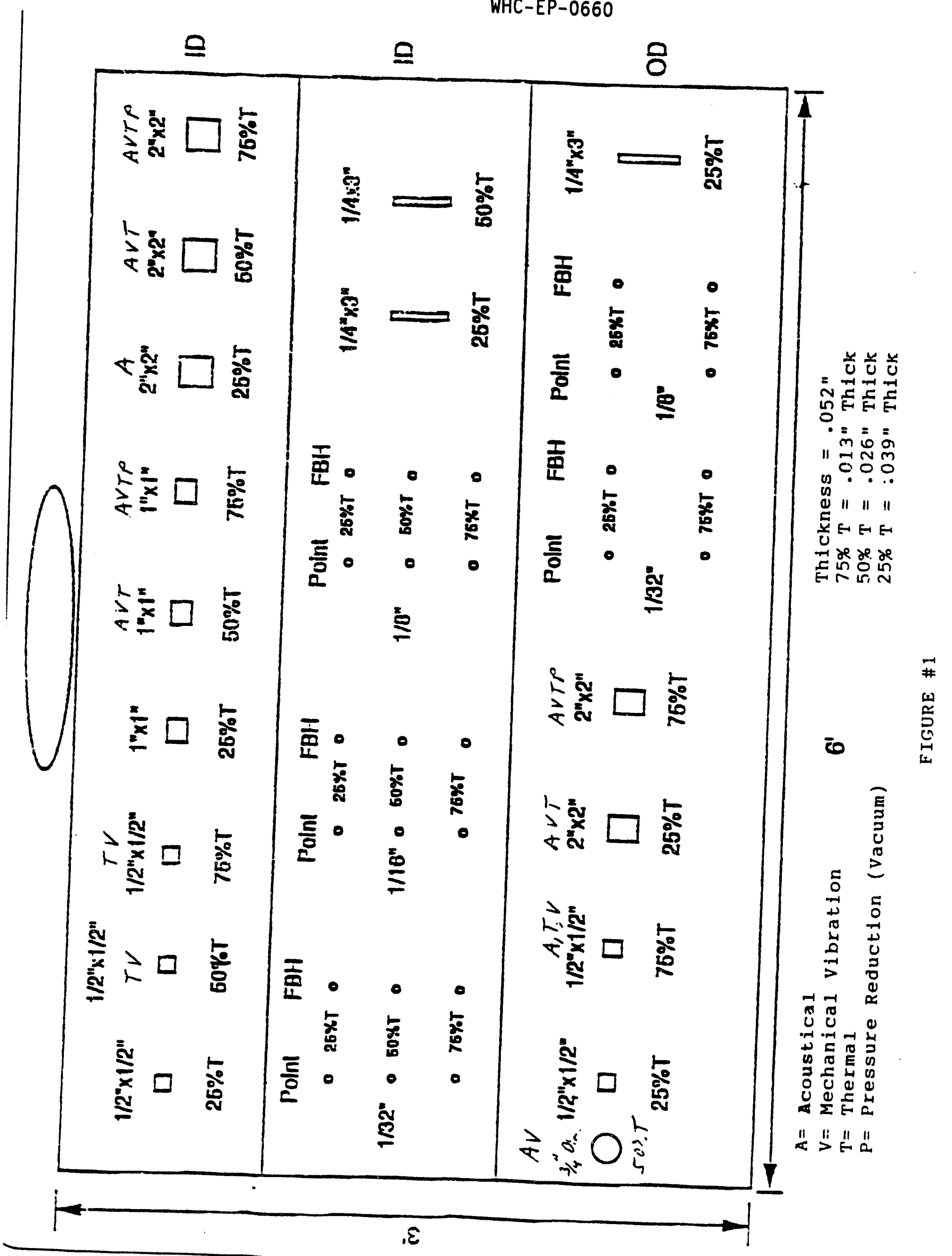


WHC-EP-0660

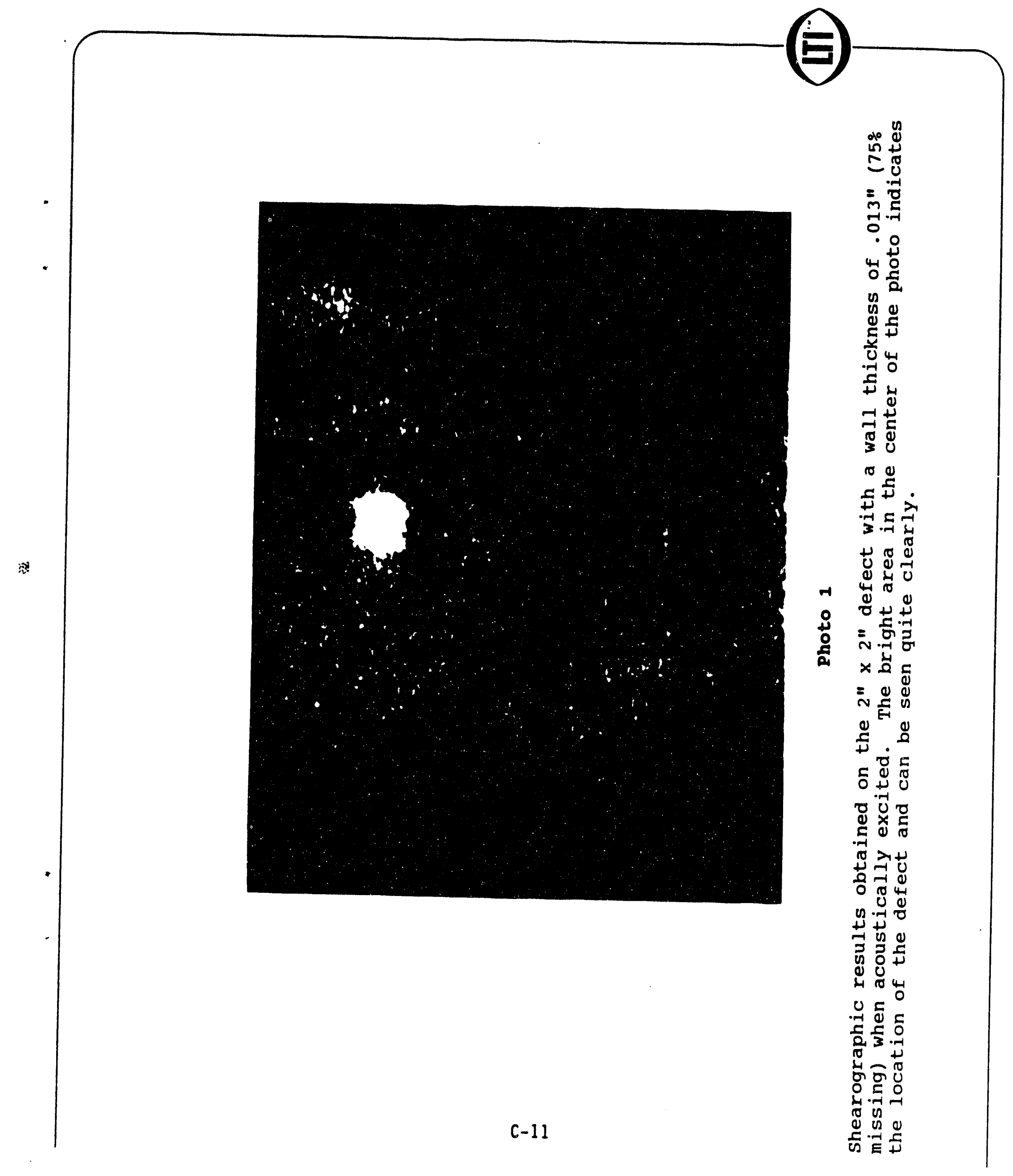




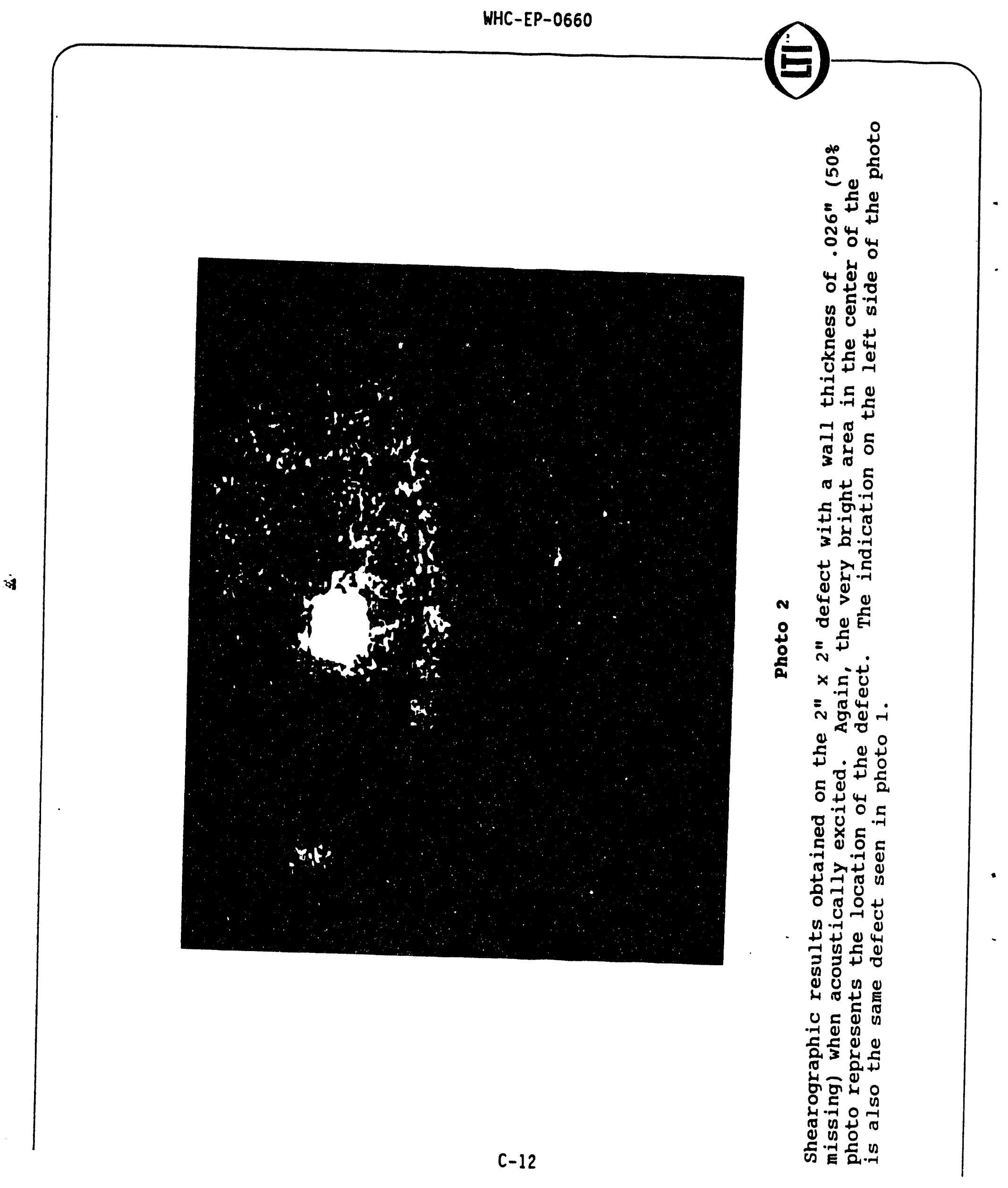


WHC-EP-0660

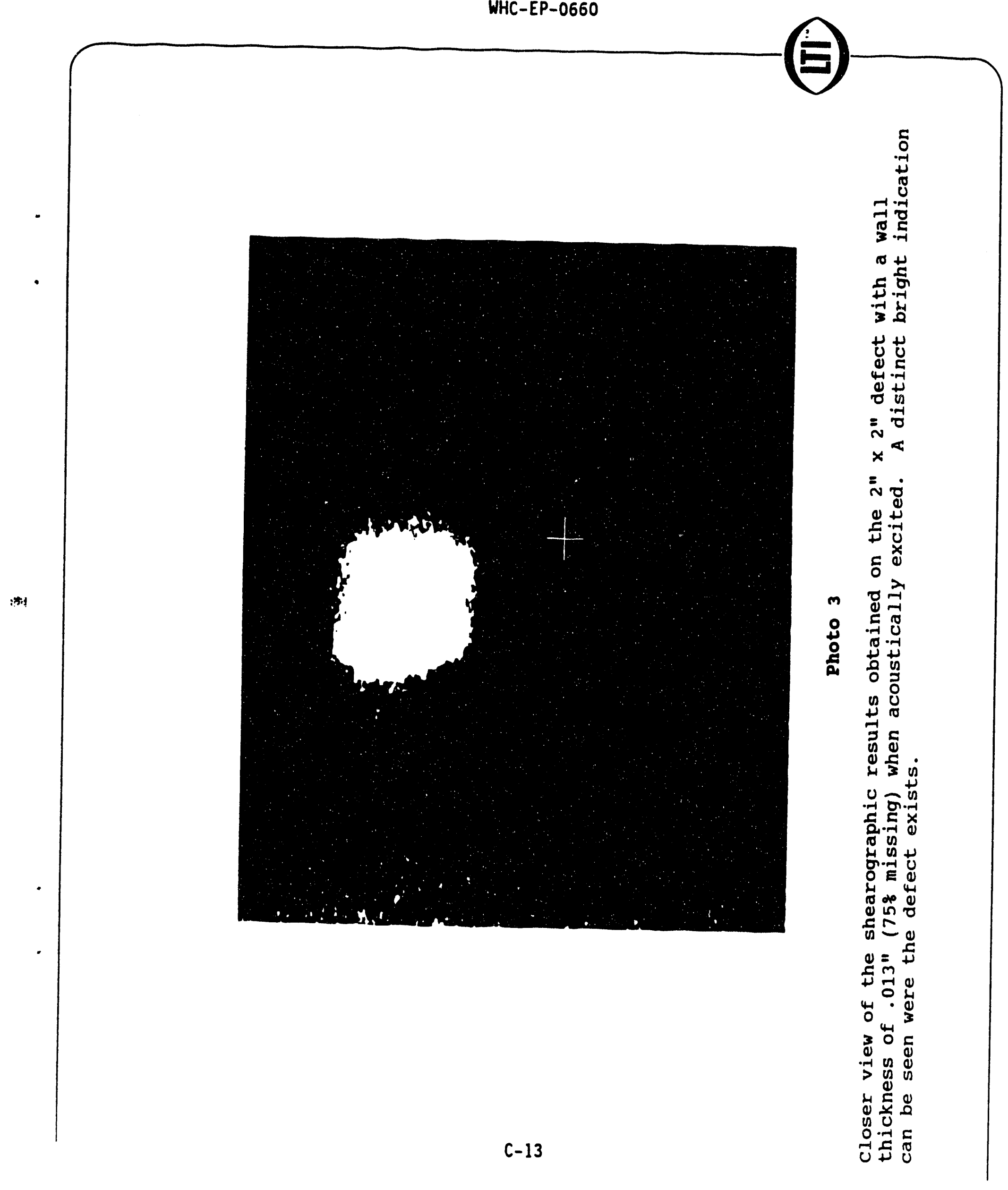




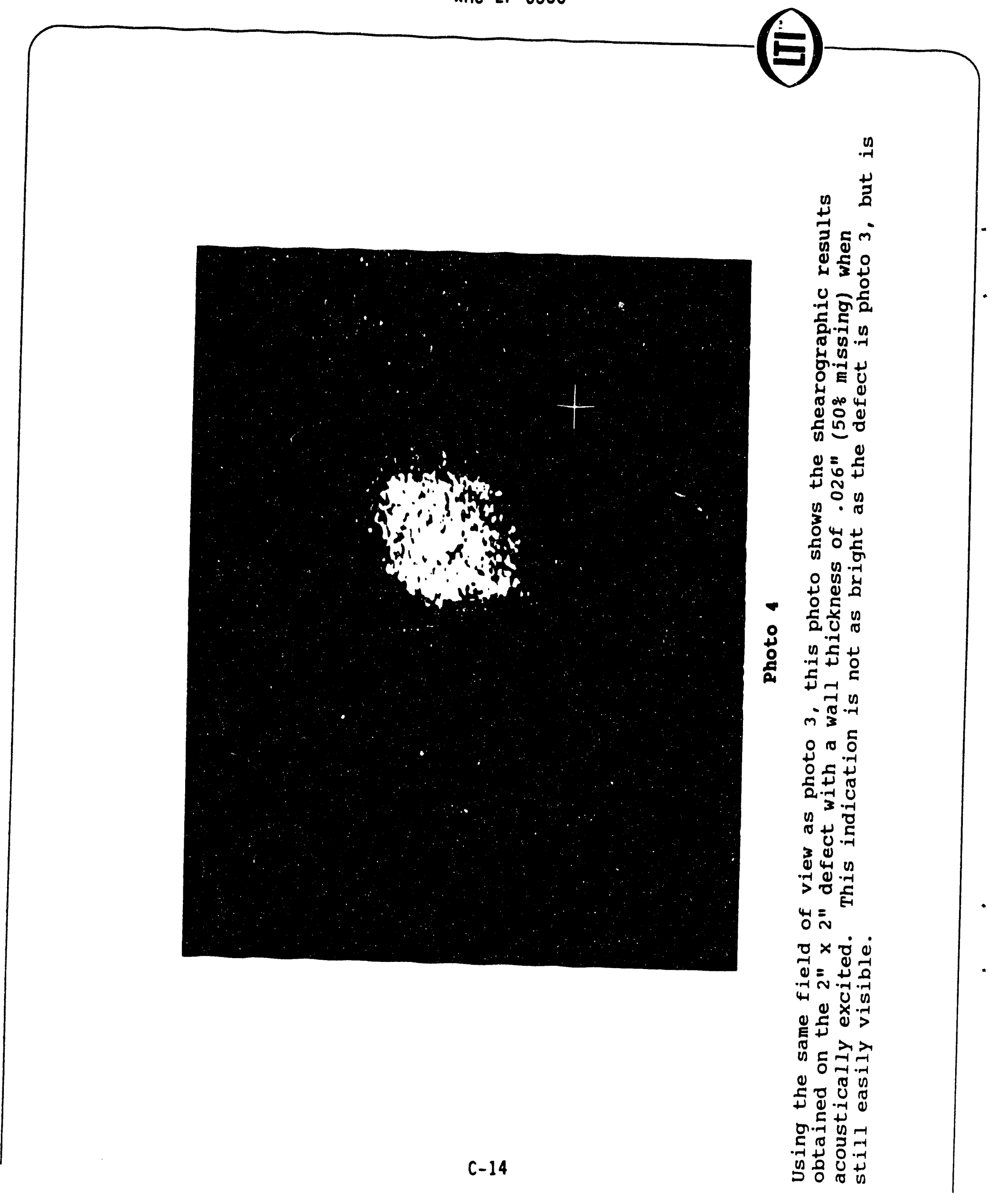




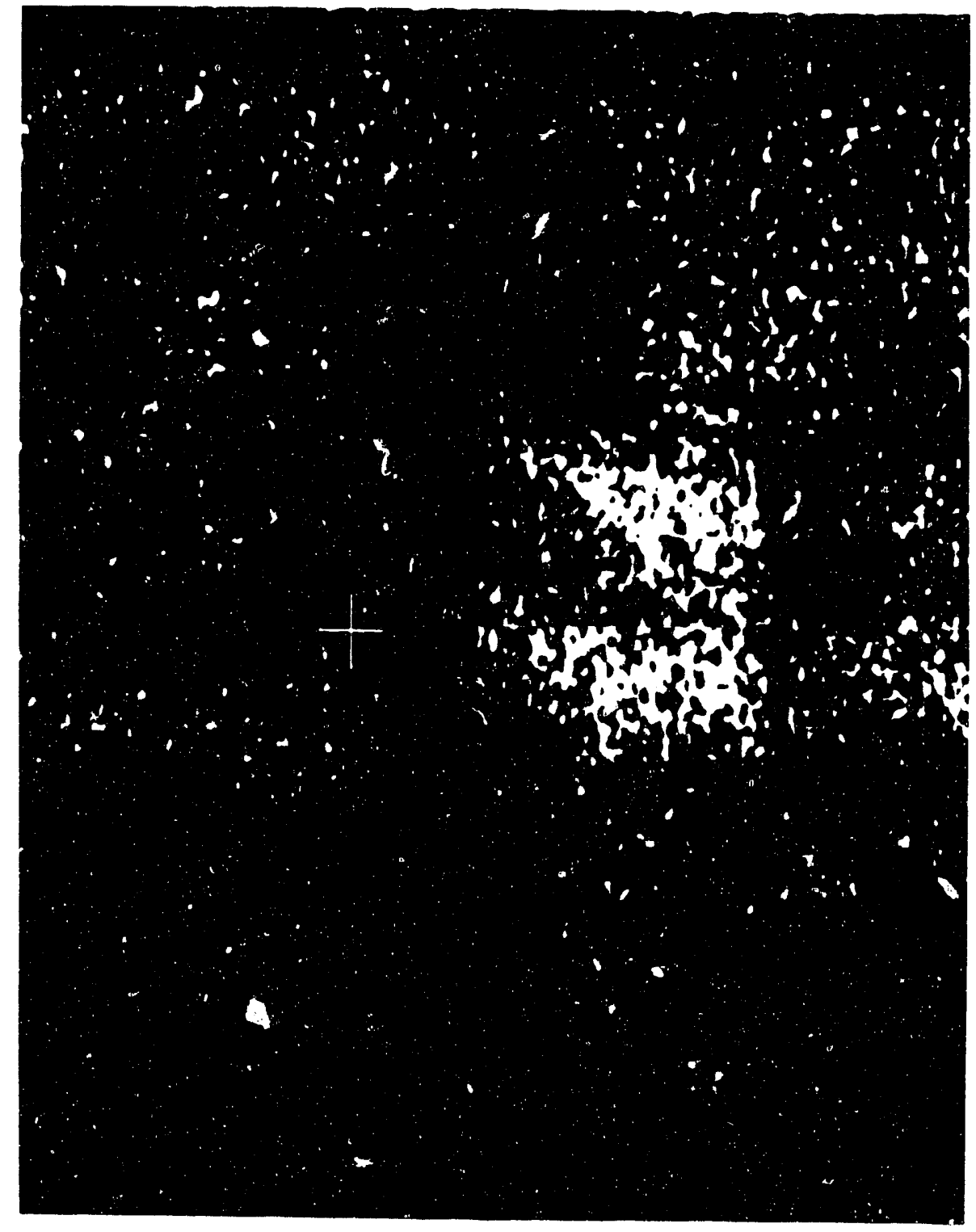

m 3

우 $0 \cdot$

을 돔 2.

(n)

匆

$30 \frac{1}{3}$

$\stackrel{0}{\rightarrow} \stackrel{0}{0}$

茨 స

它 $\times \dot{0}$

$40 x$

$0 \stackrel{x}{0}$

要

i

릉

1)

ब.न्न की

हक

- $\rightarrow$ th 0

乌。 


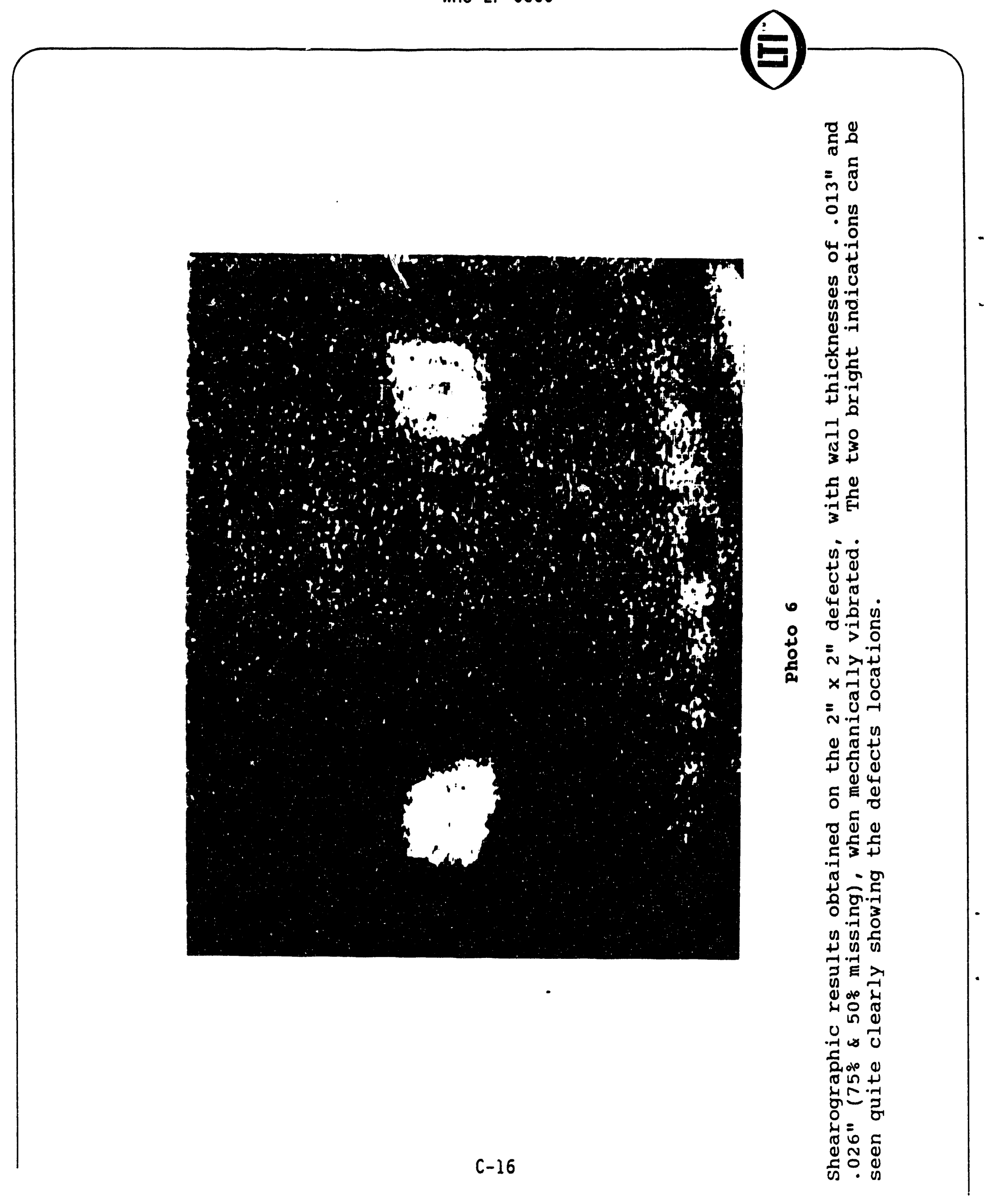



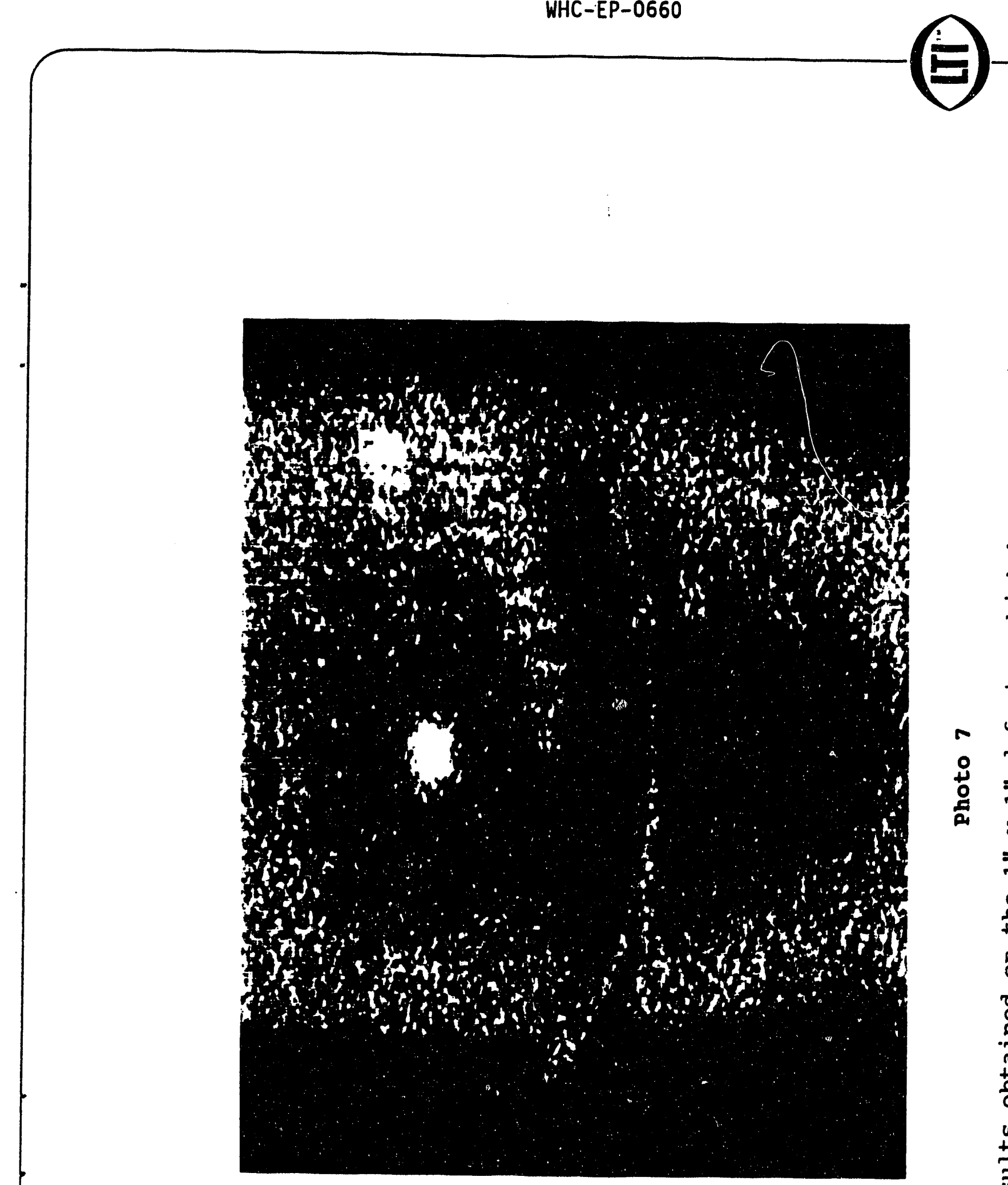


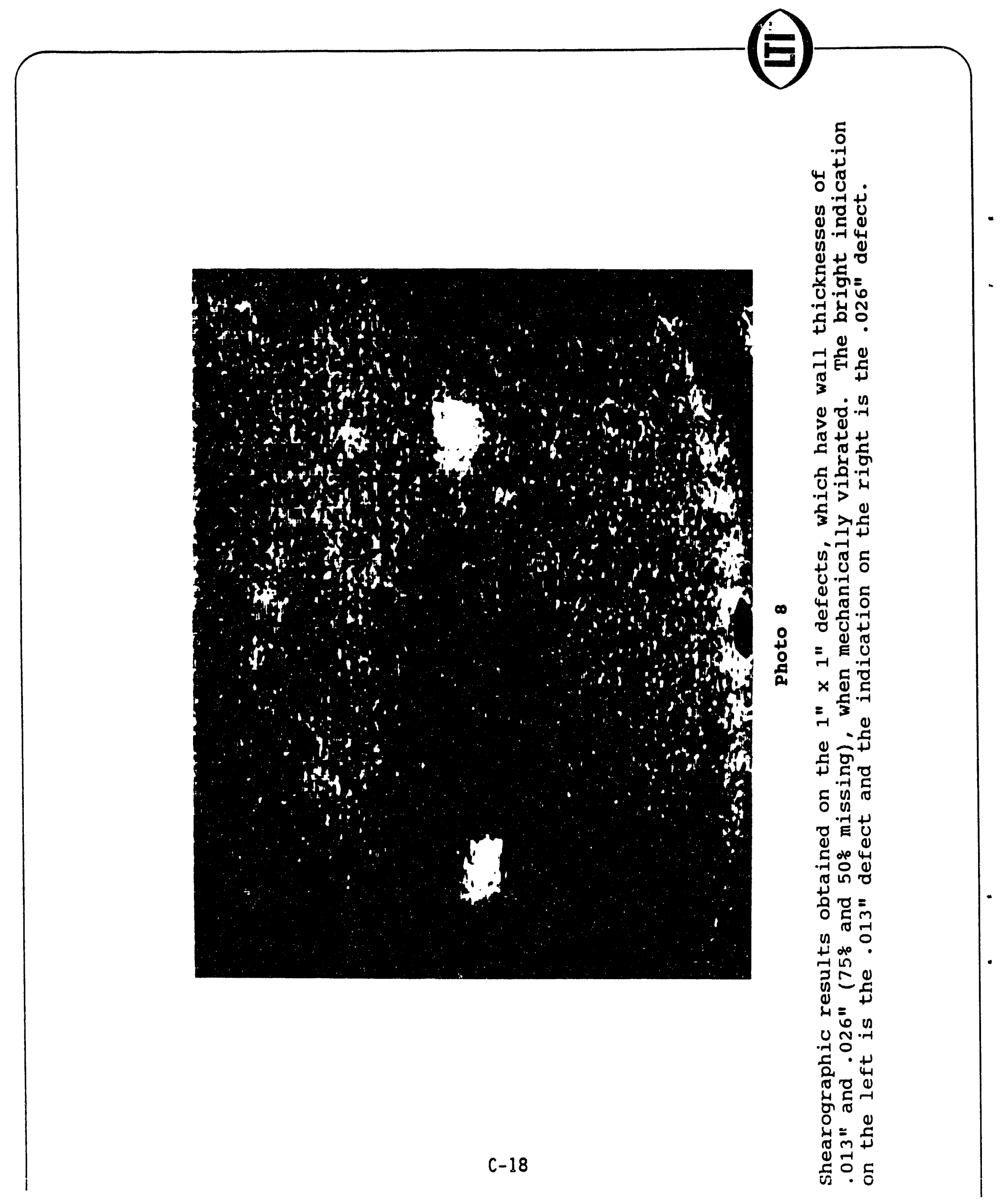




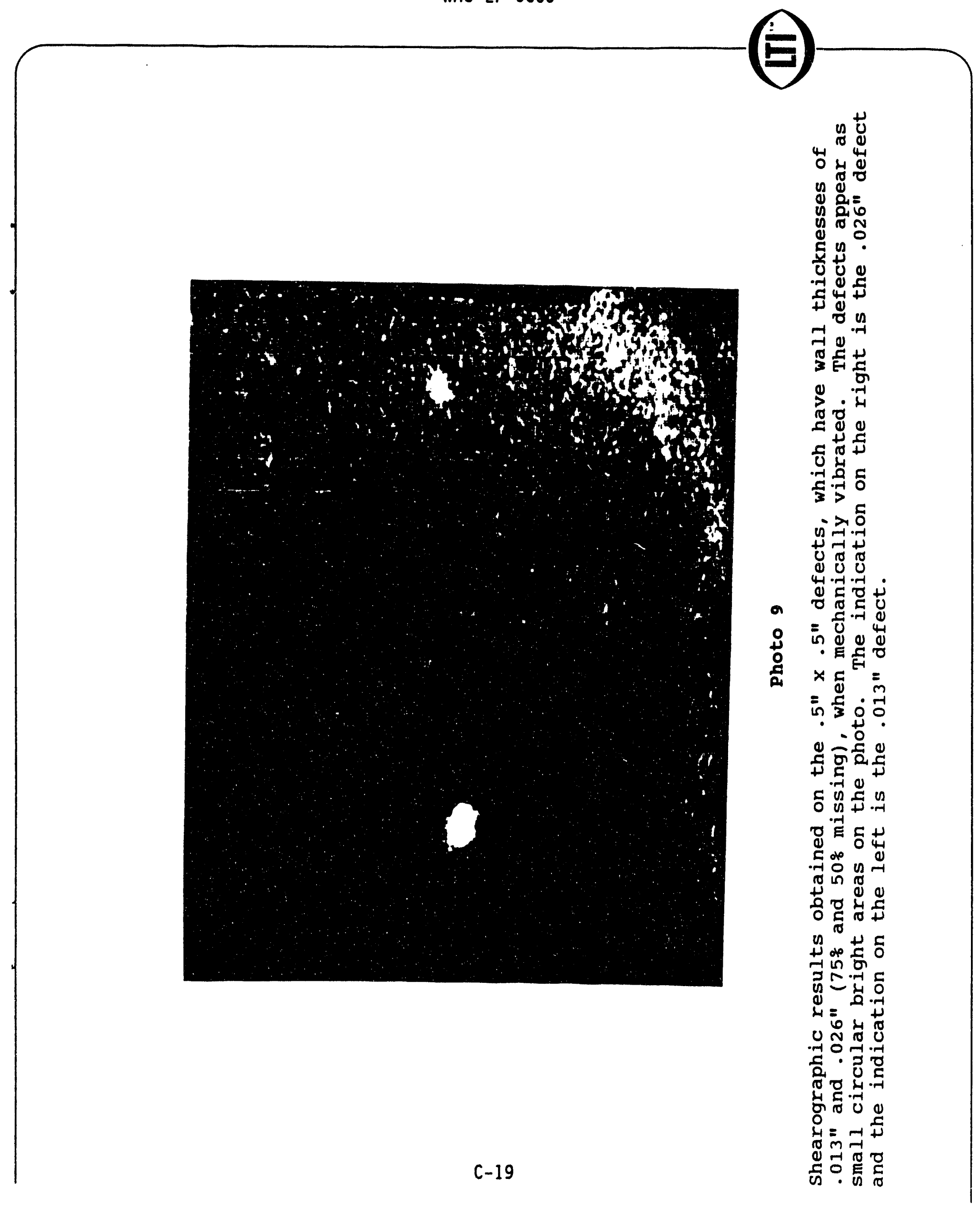



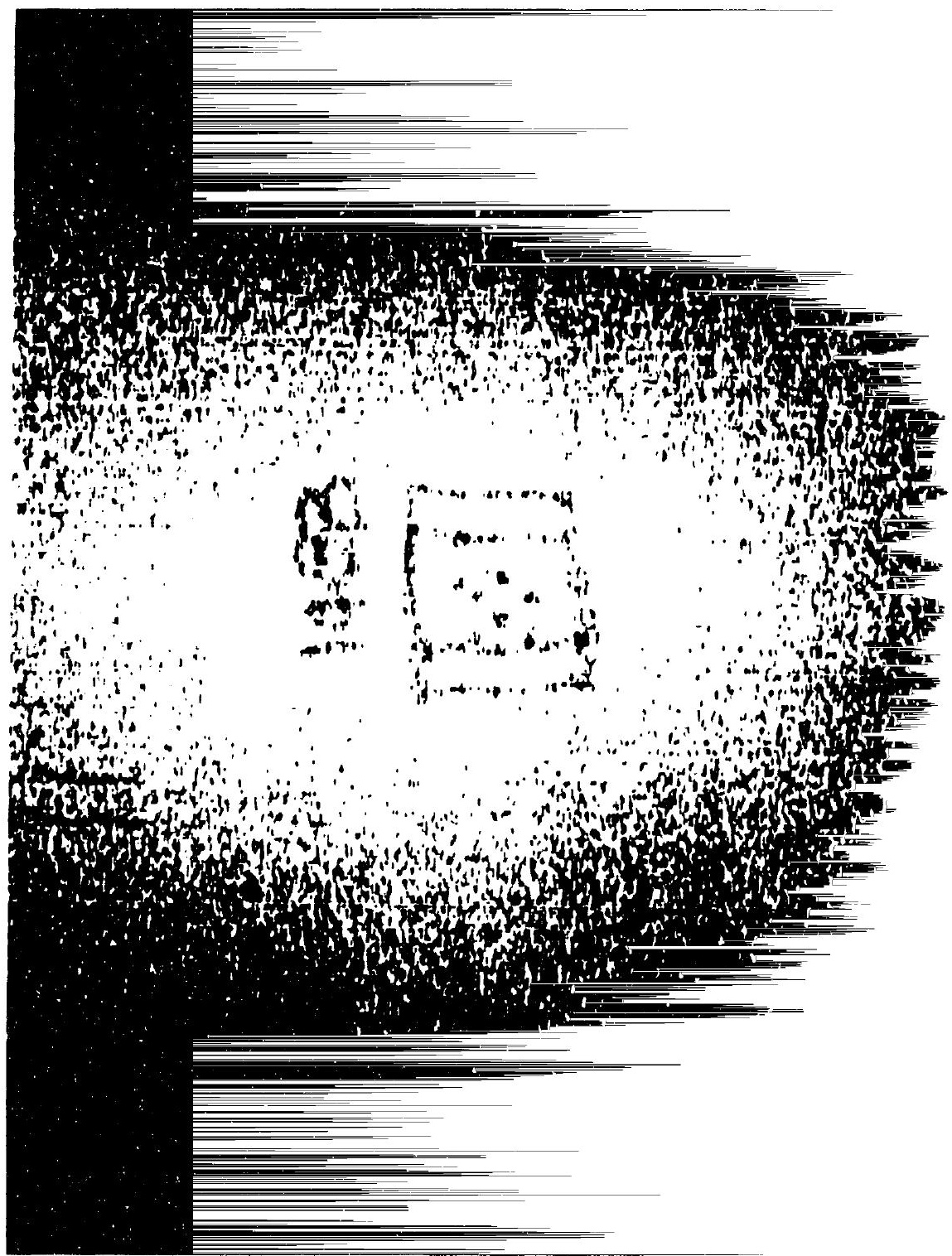


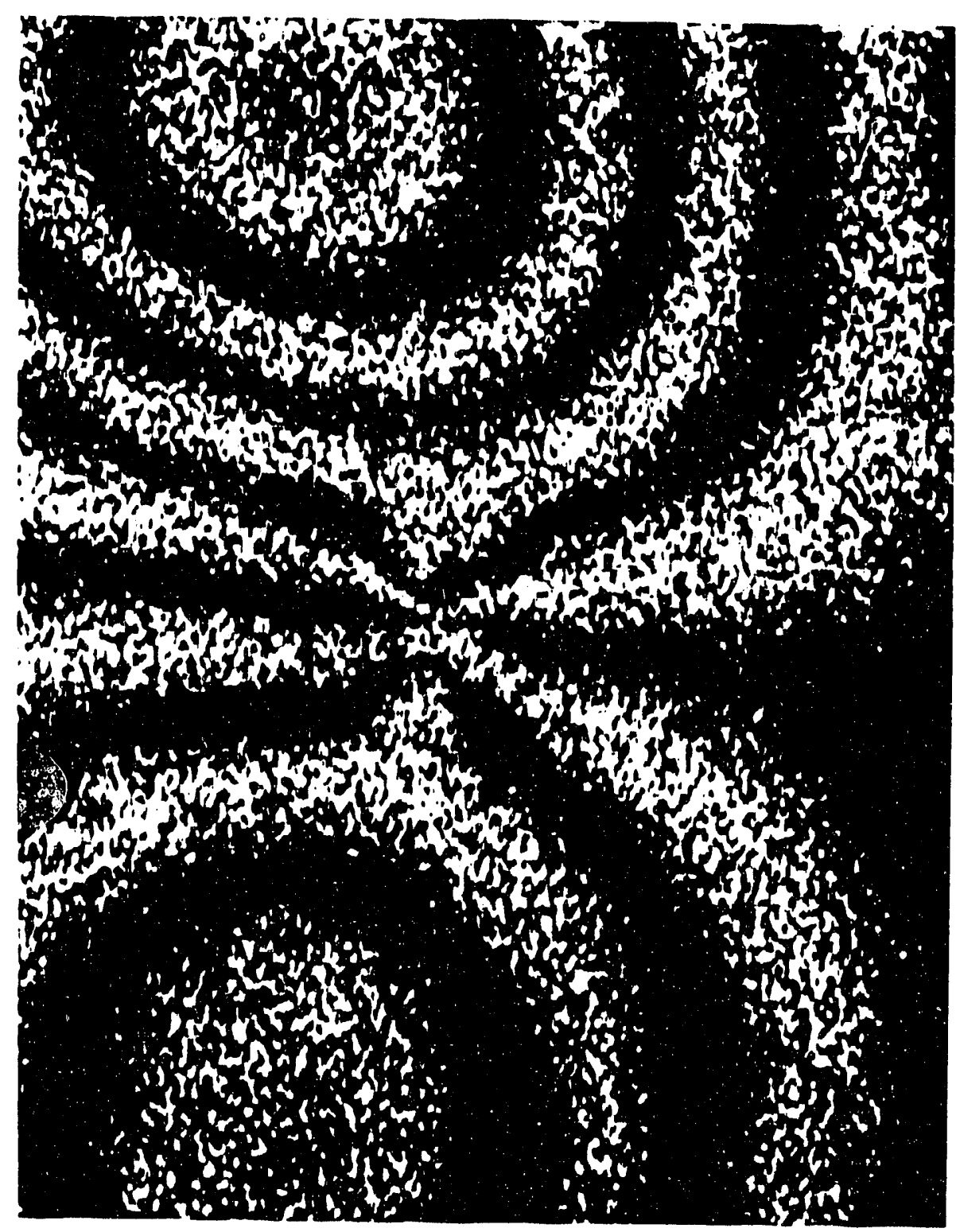

아 40

In

$=$ n.

m. n

잉 \&

- 4 员

4동요

的 $=$

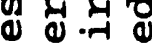

동로

-

댄

तo 4

न1 0 4

娄 굼

도 둥

Ш.ન 잉

3 ช

$+$

ช

4 0 泉

-

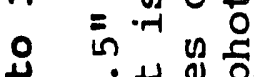

$+100$

\& $\times \stackrel{0}{0} 0$

$=4 \cdot$ 吕

in o

- 4 \& 5

四界。

00

5.

- $\frac{1}{3} 0$

Q

¿ 0 U

-

苟 is

त्र

u

म

ว

1) 4

ㄷㄷㄷㄷㄴ

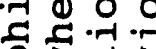

에요

正出

○ E

$\begin{array}{llll}0 & 0 & 0 & 0 \\ 0 & \text { ⿰冫 } & 0 & 0\end{array}$ 


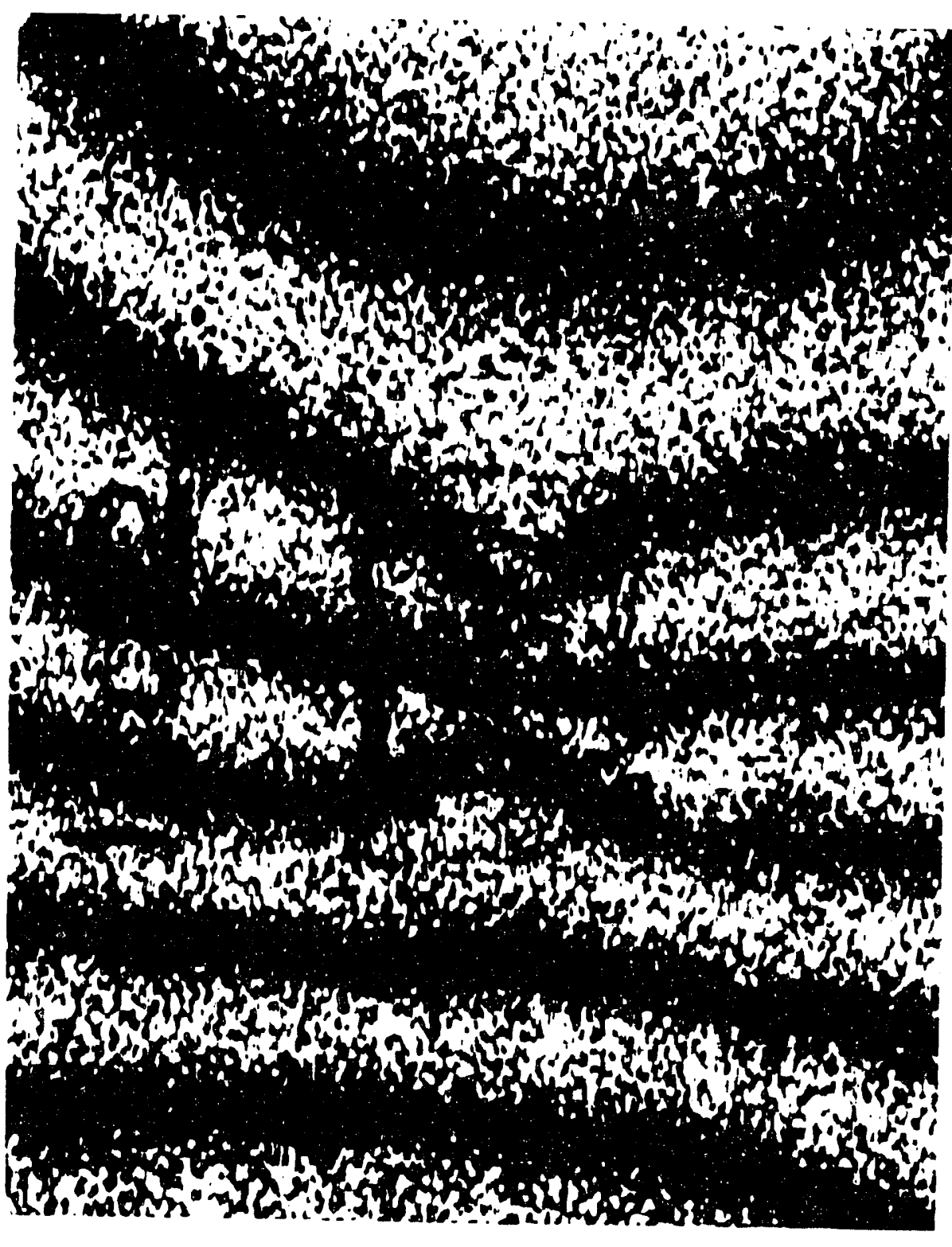

竞先

言

r d

\%

c

号先

$3=$

$+0$

(1)

4

o $\stackrel{0}{上}$

近

ธั ช

-

Q

ᄃ 40

車

to us

응 ?

n

$+\pi 0$

ป

os 0

近

U 5 卉

던

है

कै का

ठ․․․

म.

ह 덩 


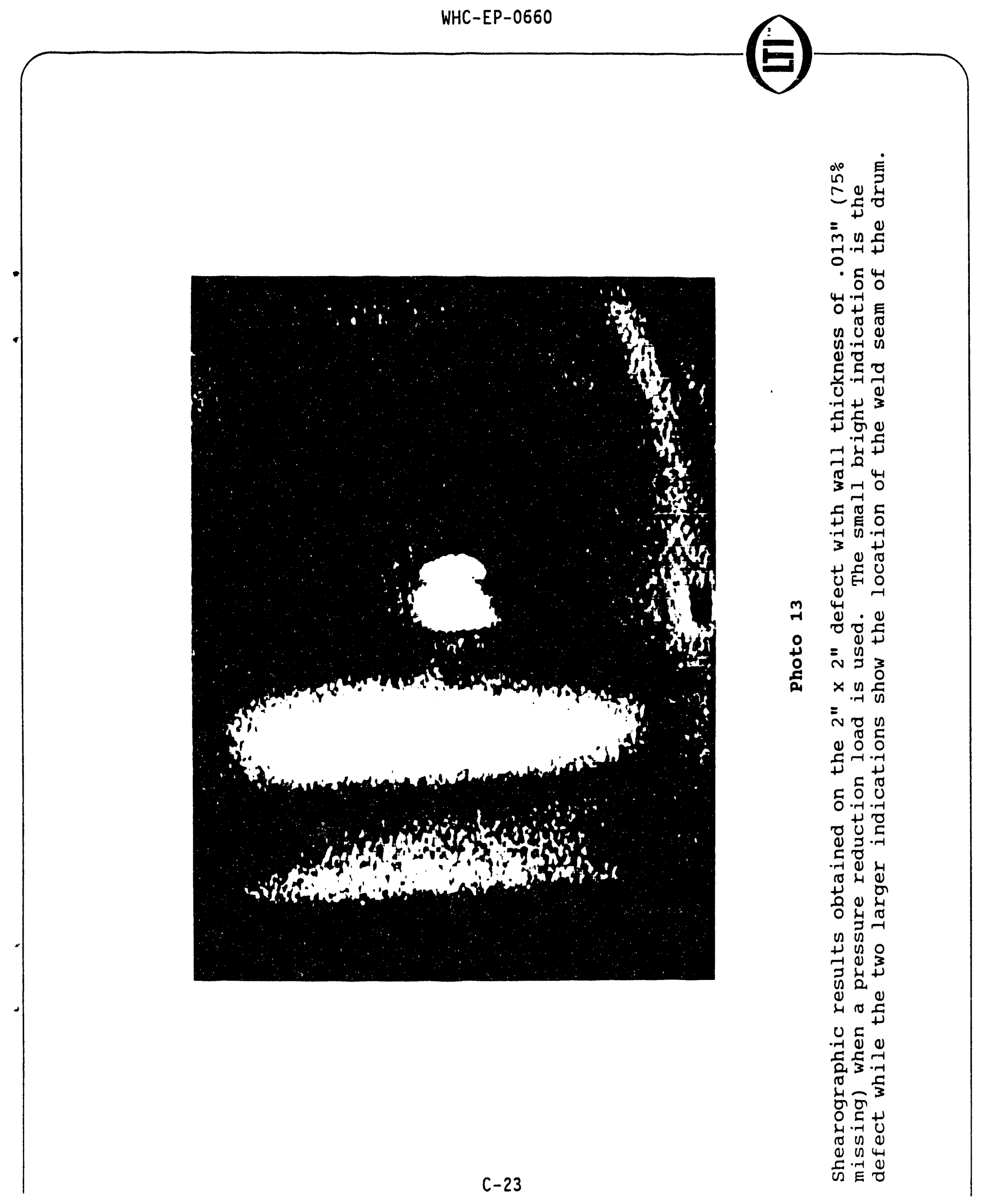




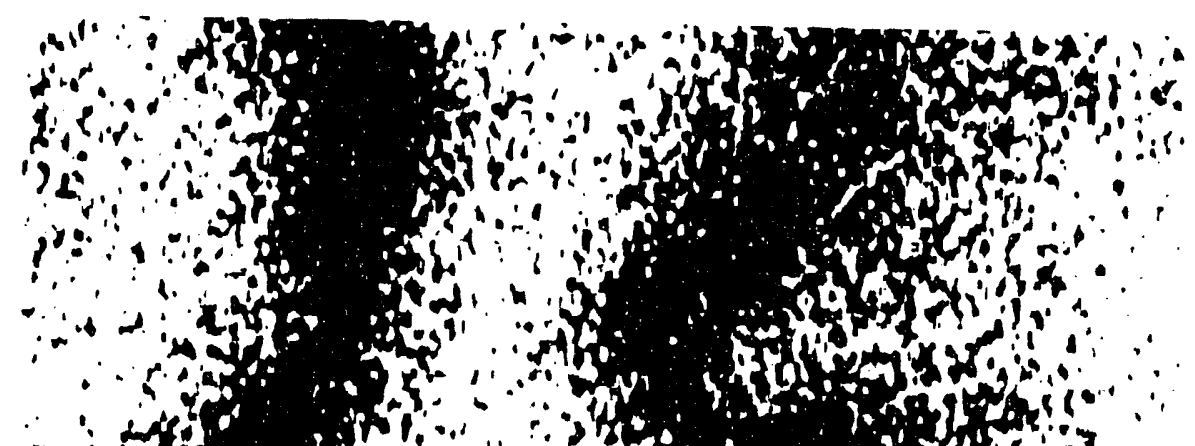

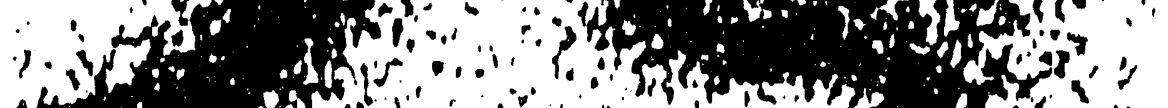

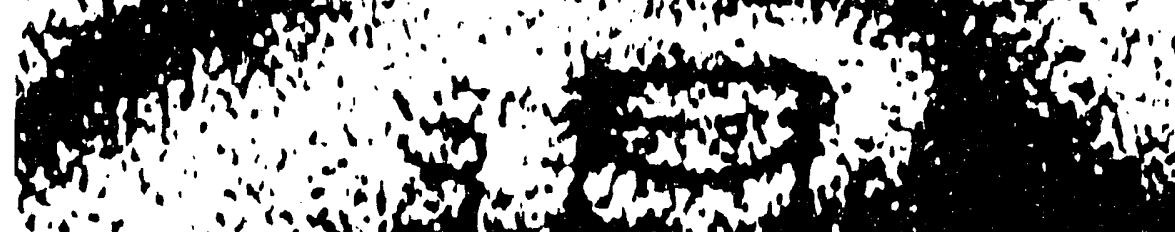
a.t.

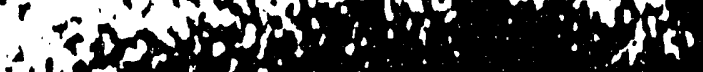

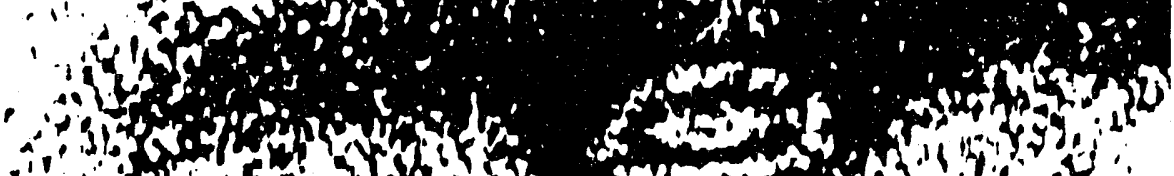

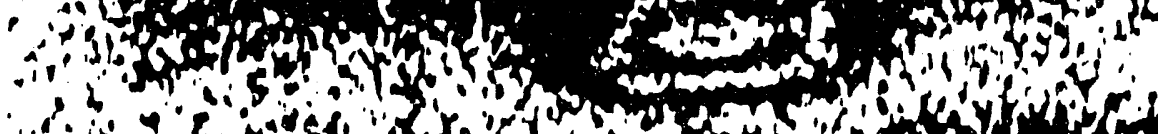

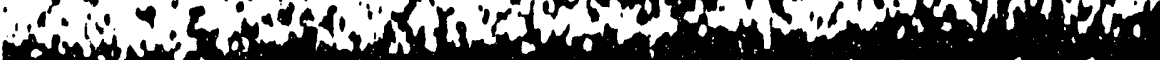

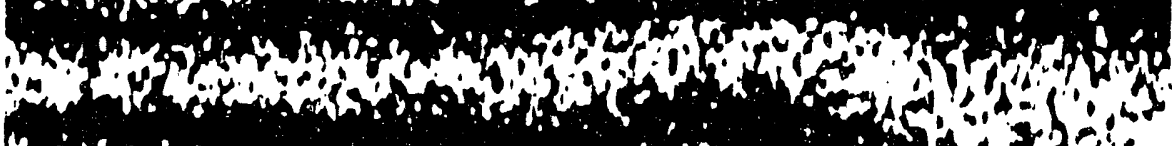

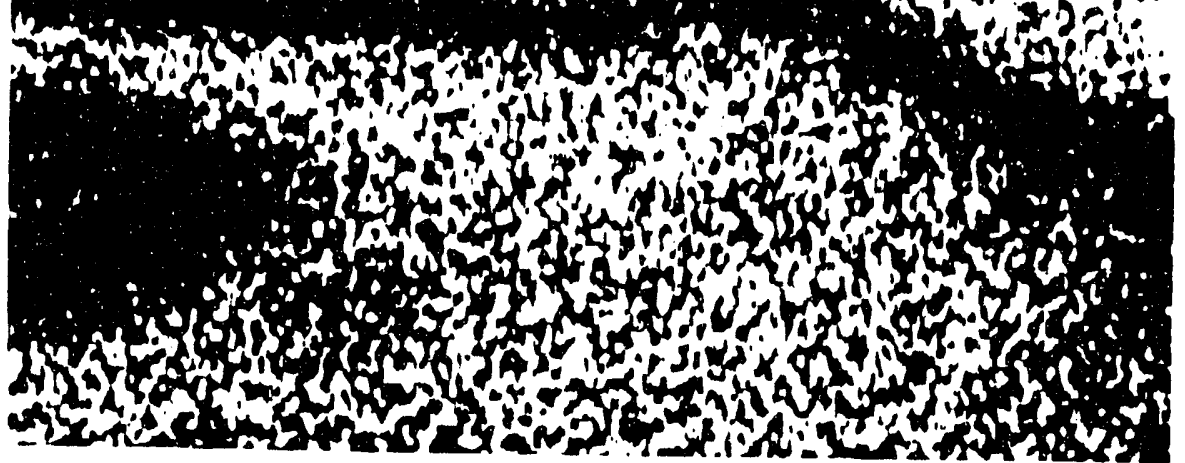




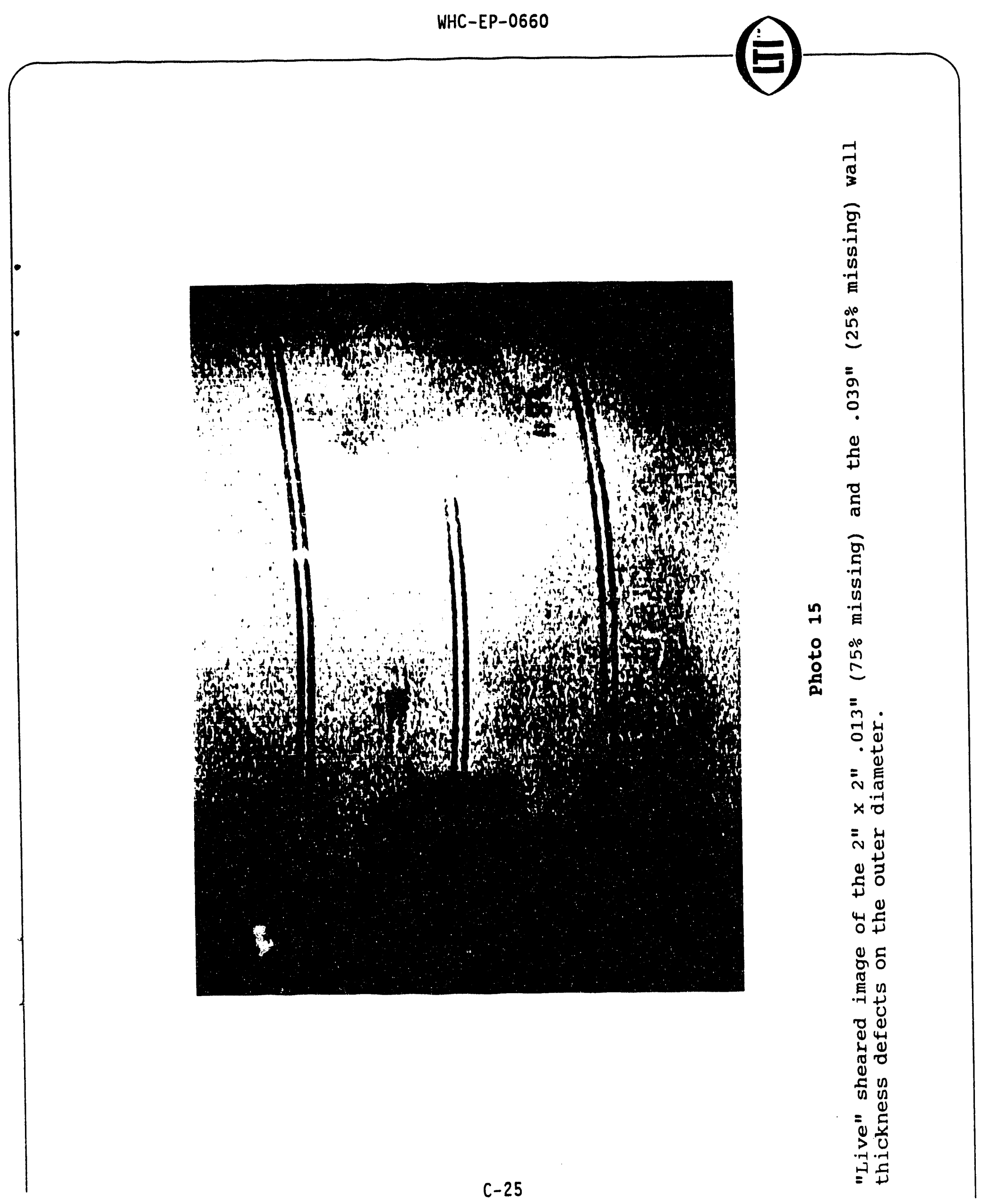




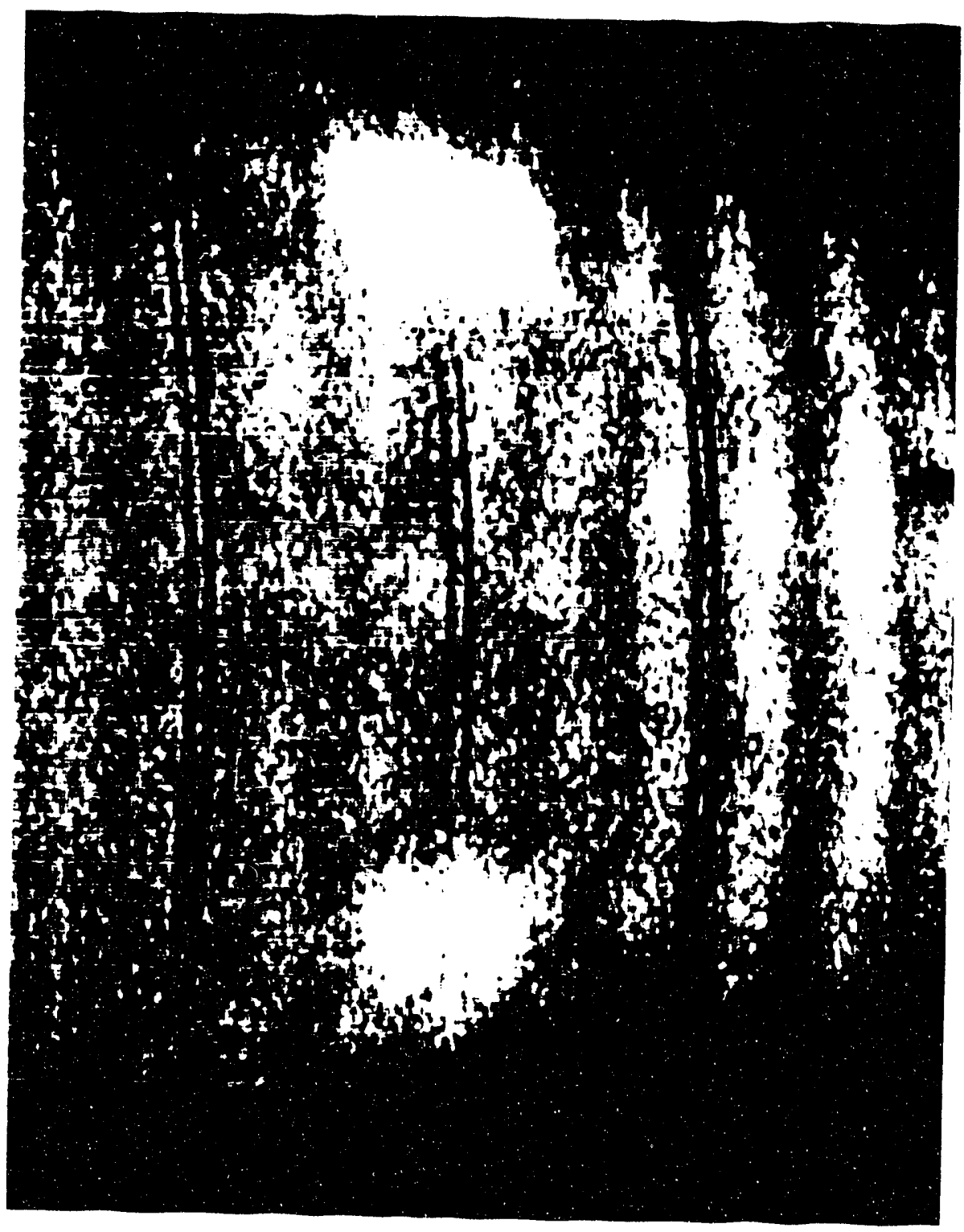

= 5

ก-

.

45

मे

\&

记 त्र.

y

$\stackrel{0}{5}$

हैं

न-1

म

开

ช

$3+\stackrel{0}{0}$

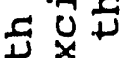

$\rightarrow 00$

$3>-1$

o 걱들

\pm 겅

(8)

0 4. in

嵌

o

$=00$

ก

$x \longrightarrow$

$=$ ป

ง $\frac{1}{3}$ 元

034

गे

Em

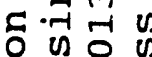

$\circ$ ขึ․․ㅇ

ช્山

望

- $\rightarrow$ ol 10 .

ก

0 ?

0 -

यकेष

$+m 03$

I $\cdot=$

\& \& 넘

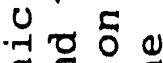
起 प्र 0

कํำ.

○

幽

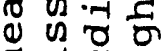

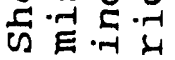




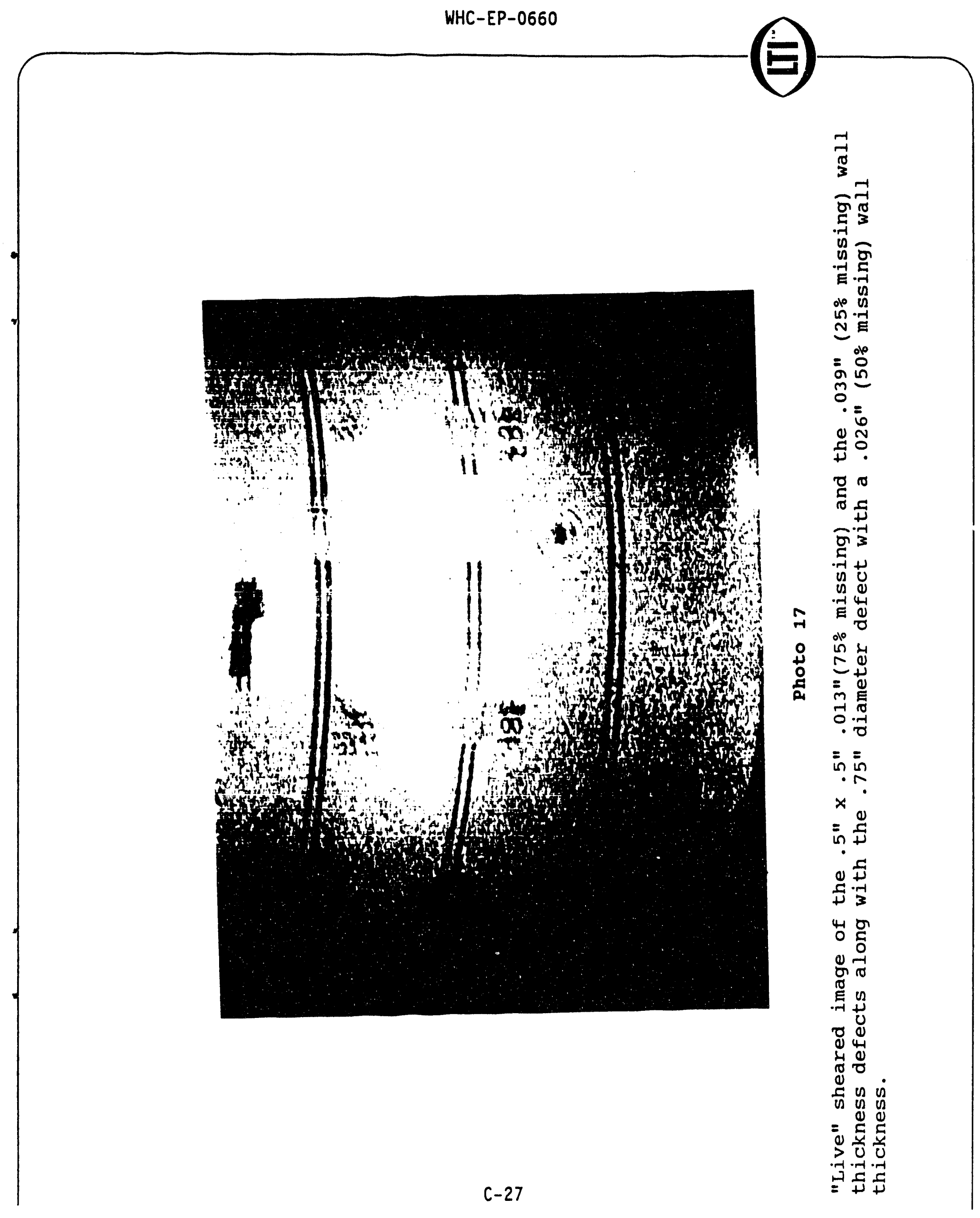




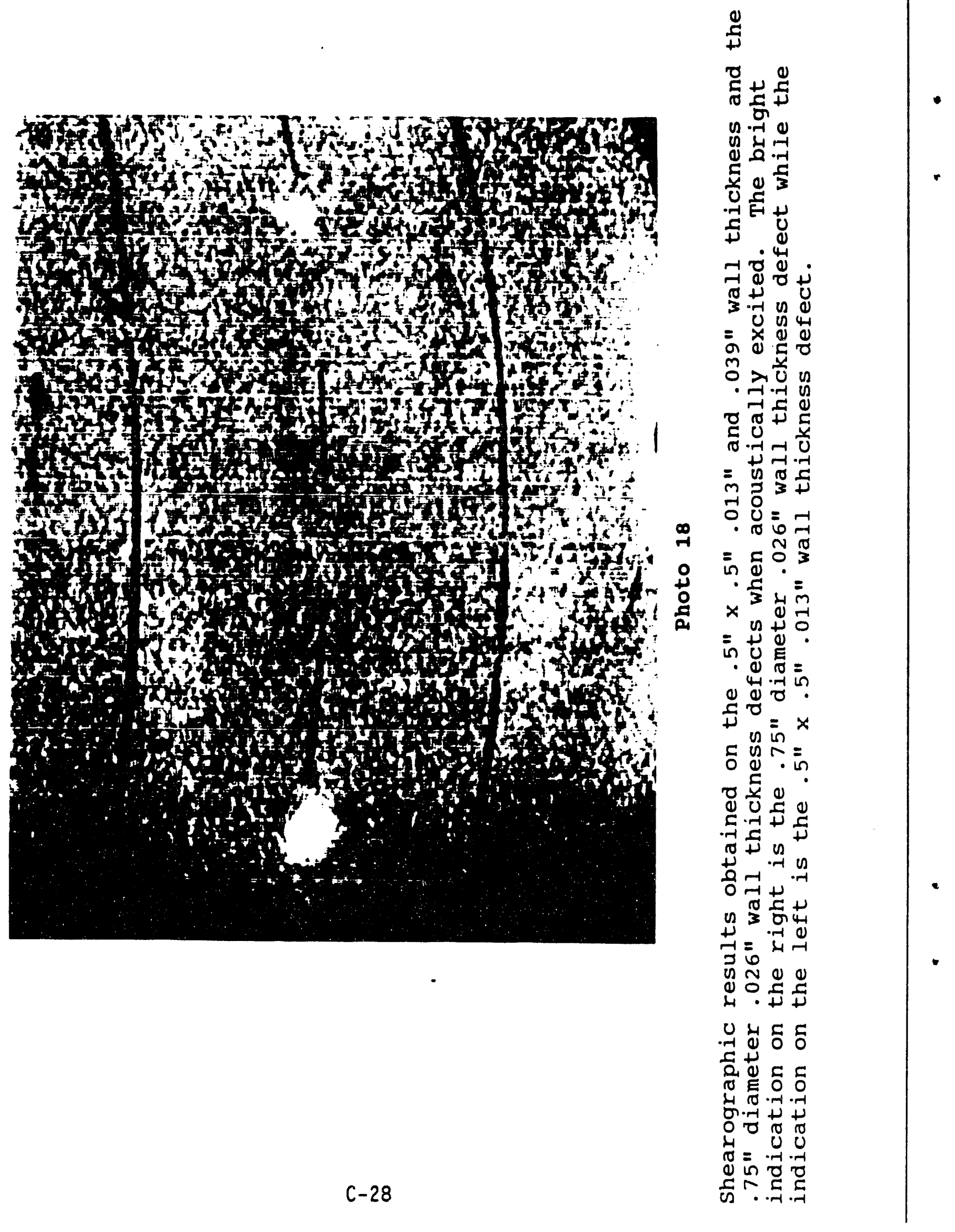




\section{DISTRIBUTION}

Number of Copies

\section{ONSITE}

3

U.S. Department of EnergyRichland Operations Office

R. M. Gordon

R3-80

R. F. Guercia

R3-80

RL Public Reading Room

5

Pacific Northwest Laboratory
D. M. Boyd
S. R. Doctor
R. L. Hockey
J. C. Spanner
K5-10
K6-96
Technical Files
$\mathrm{K} 5-26$
K5-26
$\mathrm{K} 1-11$

15

Westinghouse Hanford Company

J. J. Barker

D. L. Byron

J. A. Demiter

D. R. Duncan (3)

H5-68

M. M. McCarthy

E. P. Mertens

R. J. Roberts

B. J. Sewart

Central Files

Document Processing and

H5-37

L5-31

H5-33

N3-13

H5-33

A3-74

L6-36

L8-04

Distribution (2)

Information Release

L8-15

Administration

ᄂ8-07 

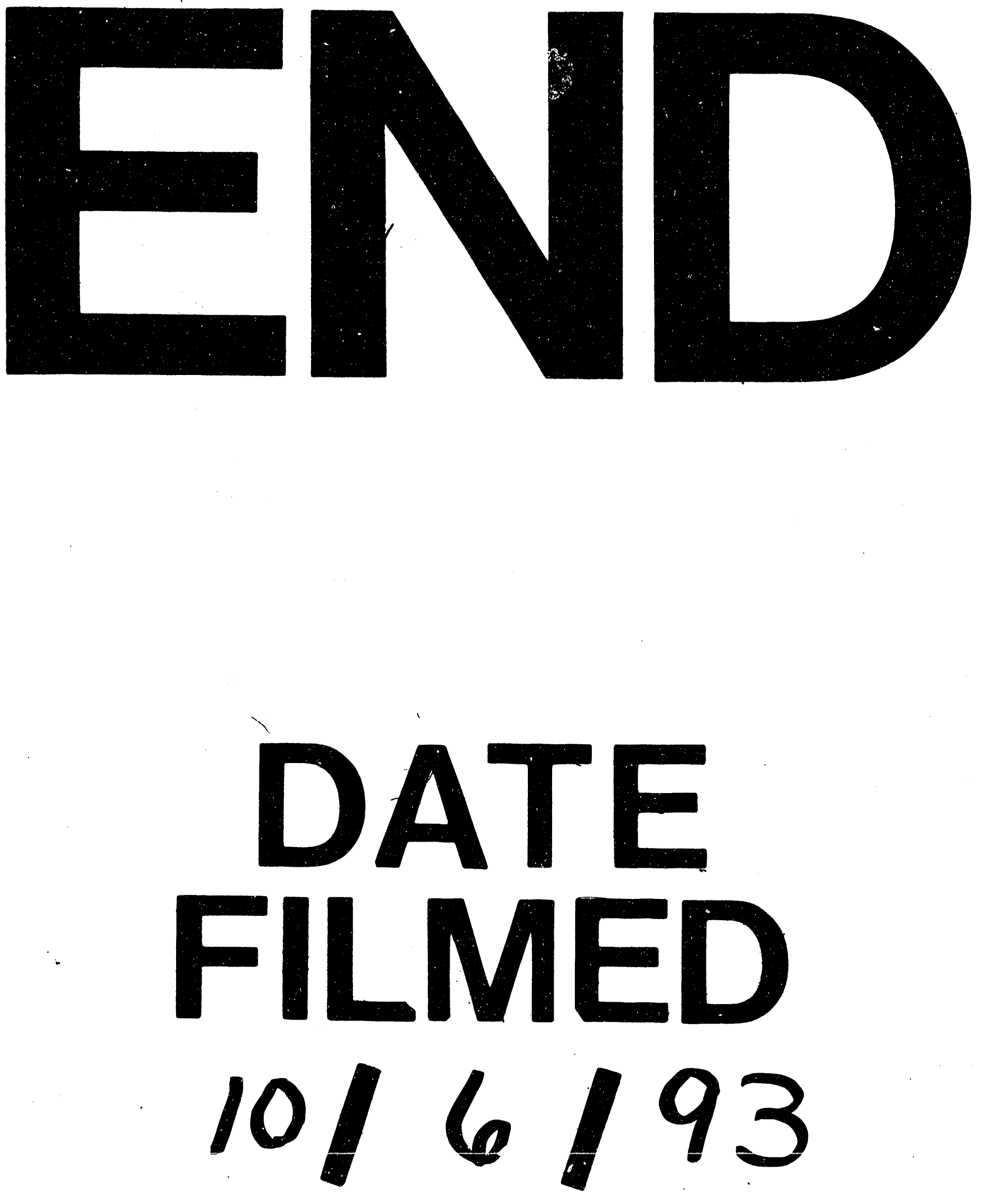

1 
